\title{
WestVirginiaUniversity
}

THE RESEARCH REPOSITORY @ WVU

Graduate Theses, Dissertations, and Problem Reports

2009

\section{Improving lumber recovery of low-quality hardwoods via finger- jointing technologies}

\author{
Colin Dougherty \\ West Virginia University
}

Follow this and additional works at: https://researchrepository.wvu.edu/etd

\section{Recommended Citation}

Dougherty, Colin, "Improving lumber recovery of low-quality hardwoods via finger-jointing technologies" (2009). Graduate Theses, Dissertations, and Problem Reports. 2752.

https://researchrepository.wvu.edu/etd/2752

This Thesis is protected by copyright and/or related rights. It has been brought to you by the The Research Repository @ WVU with permission from the rights-holder(s). You are free to use this Thesis in any way that is permitted by the copyright and related rights legislation that applies to your use. For other uses you must obtain permission from the rights-holder(s) directly, unless additional rights are indicated by a Creative Commons license in the record and/ or on the work itself. This Thesis has been accepted for inclusion in WVU Graduate Theses, Dissertations, and Problem Reports collection by an authorized administrator of The Research Repository @ WVU. For more information, please contact researchrepository@mail.wvu.edu. 
Improving Lumber Recovery of Low-Quality Hardwoods via Finger-Jointing Technologies

\title{
Colin Dougherty
}

Thesis submitted to the Davis College of Agriculture, Forestry, and Consumer Sciences at West Virginia University in partial fulfillment of the requirements for the degree of

\author{
Master of Science \\ in \\ Forestry
}

\author{
Elemer M. Lang, Ph.D., Chair \\ James P. Armstrong, Ph.D. \\ Benjamin Dawson-Andoh, Ph.D. \\ Levente Denes, Ph.D.
}

Division of Forestry and Natural Resources Department of Wood Science and Technology

\author{
Morgantown, West Virginia \\ 2009
}

Keywords: Low-Quality Hardwood Lumber; Finger-Jointing; Lumber Recovery 


\begin{abstract}
Improving Lumber Recovery of Low-Quality Hardwoods via Finger-Jointing Technologies

Colin Dougherty
\end{abstract}

The purpose of this project was to improve hardwood lumber recovery from low quality logs and lumber of Appalachian species by using finger-jointing technologies to create value-added products. Currently, there is an abundance of low quality lumber created by sawmill operations that cannot be efficiently utilized. The high presence of defects in the lumber makes processing this material costly and therefore little market exists to utilize this resource. Creating value added products from this material can help to improve forest health and alleviate the demand of quality wood products.

This project processed a total of 4,800 board feet of low-grade lumber to determine the volume of usable wood contained within low-grade lumber. Four common Appalachian species were salvaged; black cherry, soft maple, red oak, and yellow- poplar; and subsequently finger-jointed, end-to-end to create long usable stock. Lumber was then edge-glued to create solid panels which could be used in furniture manufacturing.

The recovery ratios, size distribution, mechanical and physical properties of different species were investigated and compared. Yellow-poplar produced the highest recovery ratios followed by red oak, cherry, and maple. Fingerjointed, edge-glued panels were created and their mechanical and physical properties were evaluated. Results indicated that the panels could perform suitably for their intended end-use. The recovery ratio of converting rough, lowgrade lumber, into solid panels was approximately $33 \%$. Cost/benefit analyses were performed to estimate the profitability of the process. Based on current value of solid edge-glued panels, cherry and red oak were the most profitable species to process. 


\section{Acknowledgments}

Funding for this project was provided by the Wood Education and Resource Center (WERC) located in Princeton, WV, and the WVU Division of Forestry and Natural Resources. I would like to thank Allegheny Wood Products, Coastal Lumber, Bob Barone, Stephen Franklin and Michael Weinig Inc. in Mooreseville, NC for their generous contributions needed to complete this project.

I would first like to express my sincerest gratitude to Dr. Elemer M. Lang for providing me the opportunity to pursue graduate school. His driving encouragement, support, and patience were absolutely crucial in the completion of this project.

I would like to thank the Wood Science and Technology Department and the entire Division of Forestry and Natural Resources for their support of my academic career. I would like to specifically thank Dr. Bruce Anderson, Dr. Jim Armstrong, Dr. Ben Dawson-Andoh, Dr. Levente Denes, Dr. Joseph F. McNeel, and Dr. Jingxing Wang for their support and guidance during this project as well as throughout my entire tenure at WVU. I owe Shawn Grusheky and Phil Turk greatly for their statistical advice and support. I would also like to thank Jody Gray and Paul Ludrosky for their expertise in the woodshop.

And finally I would like to express my gratitude to my entire extended family and friends for their love and support throughout all phases of my life. 


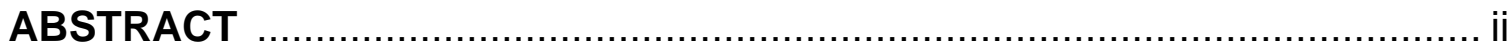

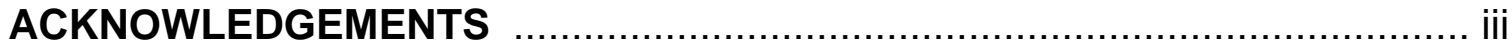

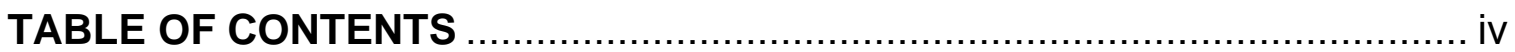

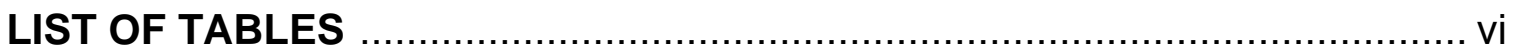

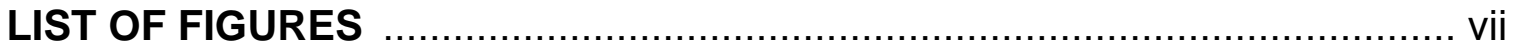

LIST OF SYMBOLS AND ABBREVIATIONS ............................................. ix

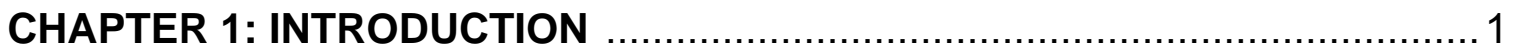

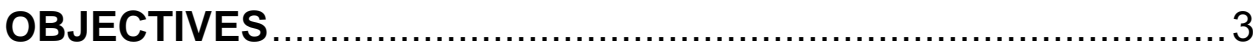

CHAPTER 2: LITERATURE REVIEW

2.1 Appalachian Hardwood Resources …......................................... 4

2.2 Utilization Improvement Efforts............................................. 5

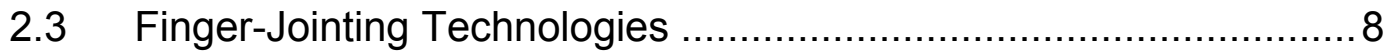

CHAPTER 3: EXPERIMENTAL METHODS

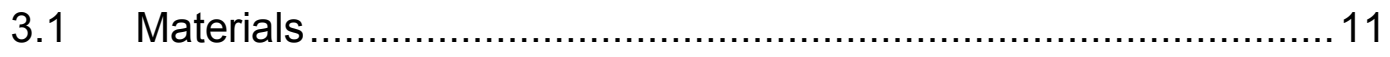

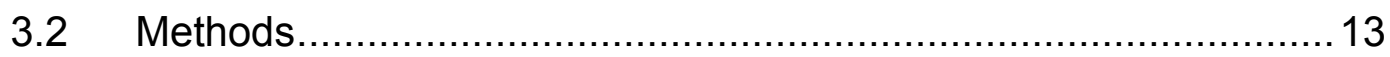

3.2.1 Acquiring and Drying Lumber ...................................... 13

3.2.2 Salvaging Methods .................................................... 14

3.2.3 Finger-Jointing Operations.......................................... 18

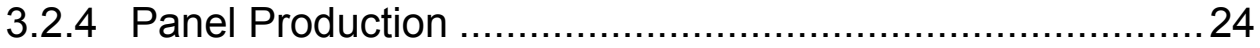

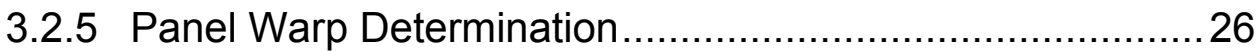

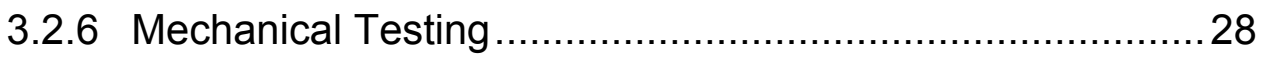

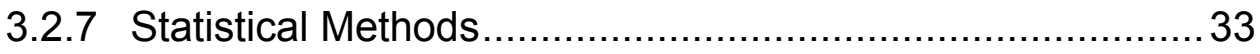




\section{CHAPTER 4: RESULTS AND DISCUSSION}

4.1 Size Distributions of Salvaged Material ...................................... 34

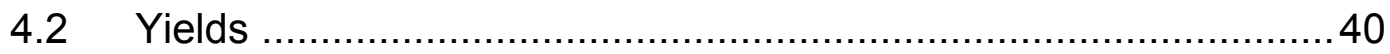

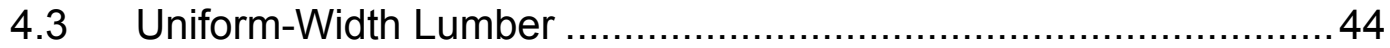

4.4 Finished Panel Yield Determination............................................46

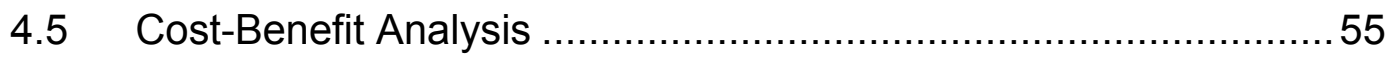

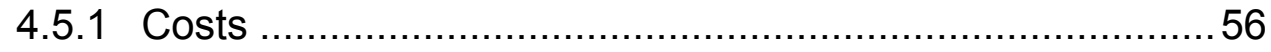

4.5.1.1 Raw Material Costs..........................................56

4.5.1.2 Operating Costs ........................................... 57

4.5.1.3 Total Costs .................................................. 59

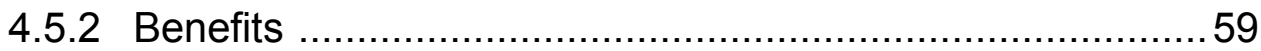

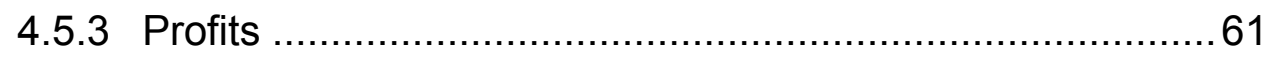

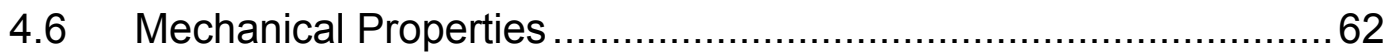

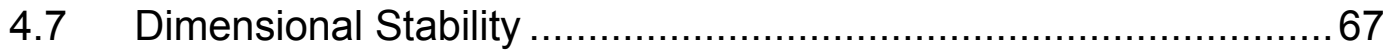

4.8 Machining and Edge-glued Panel Manufacturing Concerns..........69

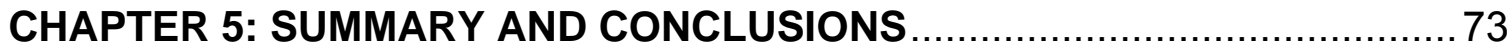

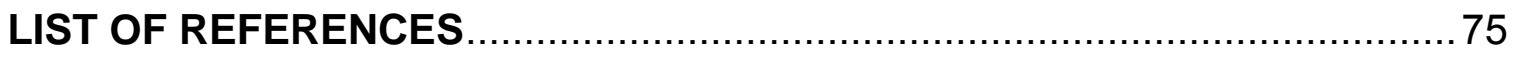

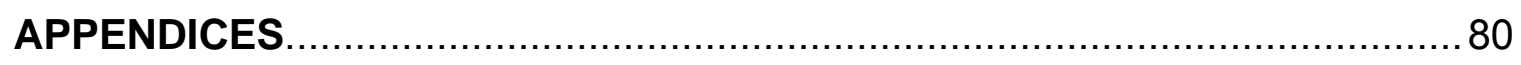

Appendix I. Results of One-Way ANOVA for size distributions of clear shorts for

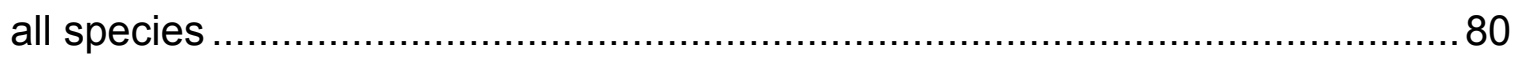

Appendix II. Results of One-Way ANOVA for Mechanical Testing ….................84

Appendix III. Results of One-Way ANOVA for 'shorts' size distribution ..............90 


\section{LIST OF TABLES}

Table 2.1 - Specifications of resin used for finger-jointing and edge-gluing operations.

Table 4.1 - Descriptive statistics of rough lumber salvaged. ….........................34

Table 4.2 - Descriptive statistics of clear material. ...........................................35

Table 4.3 - Descriptive statistics of clear lumber recovered from Phase I.......... 41

Table 4.4 - Descriptive statistics of clear lumber recovered from Phases II and III.

Table 4.5 - Yields of uniform-width shorts recovered from 1,200 BF, 4/4

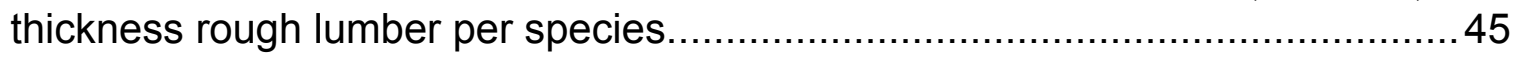

Table 4.6 - Number of width-classes and widths used to re-rip material. ...........47

Table 4.7 - Excess wood material created by forming 26 inch wide panels. ......52

Table 4.8 - Costs of No. 3A Common lumber per 1,000 BF...........................56

Table 4.9 - Total costs to process 1,000 BF rough lumber into finished panels . 59

Table 4.10 - Value of finished panels produced from 1,000 BF rough lumber per species. 60

Table 4.11 - Value of finished panel area per 1,000 BF, by species and number of width classes.

Table 4.12 - Profit from processing 1,000 BF of rough lumber based on recovered yields by species and number of width-classes used.

Table 4.13 - Stiffness (MOE x $10^{6} \mathrm{psi}$ ) results of finger-jointed and control specimens.

Table 4.14 - Bending strength (MOR psi) results of finger-jointed and control specimens.

Table 4.15 - Required clamping pressure for obtaining quality edge-glued joints for various species. 
$\underline{\text { Figure }}$

\section{LIST OF FIGURES}

Figure 2.1 - Appearance of finger-jointed, edge-glued panels. Horizontally oriented finger-joints (a) and vertically oriented finger-joints (b).

Figure 3.1 - Example of cutting pattern used to salvage rough lumber. 15

Figure 3.2 - Description of cutter-head geometry for horizontal (a) and vertical (b) finger-joints.

Figure 3.3 - Shaper set-up used to for manufacturing horizontal finger-joints.... 19

Figure 3.4 - Tearout in horizontal finger-joint caused by high feed-rate. 20

Figure 3.5 - Example of specimen with slanted fingers produced from warped shorts.

Figure 3.6 - Press used for manufacturing finger-jointed lumber at DOF. 22

Figure 3.7 - Grecon Profijoint machinery and press used to produce vertical finger-joints. 23

Figure 3.8 - Four-head moulder used to prepare blanks for edge-gluing …....... 25

Figure 3.9 - Production of edge-glued panels using panel clamps...................26

Figure 3.10 - Measurement of warp (cup) using calibrated wedge ...................27

Figure 3.11 - Environmental conditions used for panel warp determination.......28

Figure 3.12 - Determination of MOE and MOR of horizontally finger-jointed red oak test specimen by static three-point bending.

Figure 4.1 - Width distributions of salvaged shorts for all phases combined for cherry (a), maple (b), red oak (c), and yellow-poplar (d).

Figure 4.2 - Length distributions of salvaged shorts for all phases combined for cherry (a), maple (b), red oak (c), and yellow-poplar (d). 39

Figure 4.3 - Example of usable excess length of material..............................50

Figure 4.4 - Example of excess wood after trimming to 26 inch width 51

Figure 4.5 - Yield of finished panels produced from rough lumber by species and number of width classes used.

Figure 4.6 - Typical failure in bending; horizontally finger-jointed lumber (a), and vertically jointed lumber (b). 
Figure $4.7-20 \%$ wood-failure of horizontally finger-jointed red oak test

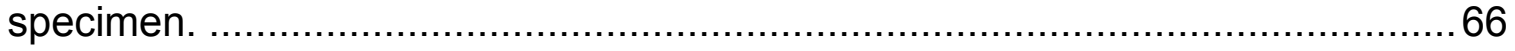

Figure $4.8-90 \%$ wood-failure of vertically finger-jointed cherry test specimen.. 67

Figure 4.9 - Example of severe cup in cherry, edge-glued panel .......................68

Figure 4.10 - Example of end split in finished cherry panel caused by snipe.....69 


\section{LIST OF SYMBOLS AND ABBREVIATIONS}

\begin{tabular}{ll}
$4 / 4$ & nominal one inch thickness \\
$\Delta$ & deflection (in.) \\
BF & board feet \\
'blank(s)' & finger-jointed lumber \\
bow & a form of warp; deviation from lengthwise flatness in a board \\
cup & warp; deviation from flatness across the width of the board \\
DH & dehumidification kiln \\
EMC & Equilibrium Moisture Content (\%) \\
F & Load (lbs) \\
ft & feet \\
hp & horse power \\
in (") & inch \\
M & moment (in-lbs) \\
MC & moisture content (\%) \\
mm & millimeter \\
MOE & Modulus of Elasticity (psi) \\
MOR & Modulus of Rupture (psi) \\
$\mathrm{I}_{\mathrm{X}}$ & moment of inertia (in ${ }^{4}$ ) \\
psi & pounds per square inch (lbs/in²) \\
rpm & revolutions per minute \\
$\mathrm{S}_{\mathrm{x}}$ & section modulus (in $\left.{ }^{3}\right)$ \\
'short(s)' & rectangular, defect-free wood salvaged from rough lumber \\
'stave(s)' & blanks, surfaced and cut to length for edge-gluing \\
warp & distortions of the intended shape of a piece of wood \\
Wt.C. & Width-Class \\
\hline
\end{tabular}




\section{INTRODUCTION}

Many factors are pushing forest products companies across the U.S. to improve forest resource utilization. Continued economic and environmental pressures force the industry to constantly attempt to improve utilization of natural resources. At the same time, the amount of low-grade lumber produced in the U.S. is on the rise (Wiedenbeck et al. 2004). As these pressures mount, more forest products manufacturers are seeking alternative value-added processing methods to utilize this low-quality resource (Lin et al. 1994). Developing new methods and processes to efficiently process this resource is a major research priority (Shepley et al. 2004).

Cumbo (2003) stated the annual hardwood lumber production has been estimated at greater than 13 billion board feet. However, due to changes in markets for hardwood lumber and a slowdown in the U.S. economy, hardwood manufacturers are having difficulties remaining profitable leading to production reductions and mill shutdowns. The lack of profitability can be especially harsh for manufacturers dealing with large volumes of low-grade material as profit margins are low and there are few markets (Cumbo 2003).

More low-grade lumber is being produced as a result of an increased volume of low-quality hardwood logs being harvested. Evidence suggests there is an "over-abundance" of low-value, small diameter timber in forests in the eastern United States (Cumbo 2003). The amount of higher-grade hardwood 
lumber available will continue to decline forcing manufactures to find a market for this low-grade material (Meyer 1996). The level of interest placed on developing and maintaining markets for this material should increase as low-grade lumber production increases.

Creating valued-added alternatives for processing this material could encourage foresters to remove lower-quality material from the forest, resulting in better forest health and increased profits for forest landowners and the forest products industry. Establishing markets for this material will allow both landowners and the forest products industry to benefit from improved utilization of low-quality material (Shepley et al. 2004). A trend towards smaller and more diversified markets for low-grade lumber may be developing as a result of the changes in larger, more traditional markets for this material (Cumbo 2003).

Unfortunately this lumber contains a large amount of defects, as well as a high percentage of juvenile wood, making it more prone to warp. As a result, the cost to process this material is relatively high.

Shepley et al., (2004) investigated opportunities to increase utilization of No. $3 \mathrm{~A}$ Common ( $3 \mathrm{AC})$. It was determined that lumber yields could be improved by salvaging narrow width and short length pieces from the lumber. Fingerjointing operations are ideal for reconstituting small pieces of lumber into longer, usable stock.

This project investigated the feasibility of utilizing No. 3AC hardwood lumber to create solid hardwood panels for use by furniture and cabinet industries. 


\section{OBJECTIVES}

The overall objective of this project was to improve lumber recovery of low-quality lumber by salvaging small, clear material (shorts) and to use fingerjointing technologies to create value-added products. Low-grade (No. 3A Common) lumber was processed to recover the largest volume of usable, clear lumber possible. Clear pieces were then ripped into uniform width-classes and finger-jointed end-to-end to create long, usable stock. The lumber was then surfaced and edge-glued to create solid hardwood panels. The yields and sizedistributions of clear shorts were analyzed, and the volume of finished panels was determined. Specific objectives of this project were:

1. To investigate and numerically determine the recovery ratio for different sequential combinations of drying/salvaging/jointing/ and size-dressing operations.

2. To develop and document species specific technologies for converting shorts into marketable, profit generating products.

3. To experimentally determine the competitive physical and mechanical properties of the new products.

4. To evaluate the profitability of the manufacturing processes using cost-benefit analyses.

To achieve the above mentioned objectives, the following research methods were performed. 


\section{LITERATURE REVIEW}

\subsection{Appalachian Hardwood Resources}

Buehlemann et al., (2007) stated that $55 \%$ of all hardwoods harvested in the northeastern United States consist of Appalachian hardwoods. These forests contain primarily of oak, maple, yellow-poplar, and black cherry hardwood trees. Furniture, cabinet and flooring industries are the largest users of this lumber. Currently there is an abundance of smaller timber in the forest creating lower grade lumber and is therefore a lack of high-grade lumber to satisfy the needs of furniture and other wood product companies.

It is estimated that small diameter hardwoods consist of $32-42 \%$ of the growing volume of timber and $93-95 \%$ of total trees growing in the northeast. Greater utilization of small-diameter logs results in higher percentages of lowquality lumber produced. As a result, more than $60 \%$ percent of hardwood lumber produced is graded No. 2 Common or lower (Bumgardner et al. 2001).

Creating markets for this low-grade lumber can have many benefits. Silvicultural treatments become more financially attractive for harvesters to remove smaller diameter timber and these treatments can help improve forest health (Bumgardner et al. 2001). Forest thinning practices are common in forest management plans to remove small-diameter or otherwise lower quality timber and promote growth of higher value trees as well as to reduce forest fire hazards 
(Cumbo et al. 2004). Much of the low-quality material removed from the forest is often chipped and sold to pulp/paper industries. Opportunities may exist to create value-added products from this material and promote its extraction from the forest.

Currently the largest market for low-grade lumber is the pallet industry, followed by industrial uses and flooring. However, the pallet industry has recently seen an increase in recovery, repair and reuse of pallets resulting in reduced demand for low-grade lumber (Cumbo et al. 2004). The results of these factors necessitate research to develop methods to efficiently process and market this under-utilized material. The efficient use of this renewable resource can be achieved only if a variety of products can be created from the lumber.

These challenges emphasize a need to diversify markets and improve recovery of this low-grade material. This had led to many research projects focused on improving utilization of forest resources.

\subsection{Utilization Improvement Efforts}

Timber is converted into lumber at the primary sawmill and graded based on the amount of defects present. Rough mills then purchase varying grades of lumber to process and produce components for furniture and wood product industries (Zuo et al. 2003). Wood products companies need to efficiently convert this rough lumber into marketable products to remain profitable. The 
rough mill removes undesirable wood characteristics and defects from the lumber. The resultant clear lumber may then be further processed by moulding, finger-jointing or edge-gluing to create panels or other value-added products.

Rough mills generally purchase a variety of lumber grades in order to cut the required parts needed for their customers. Lumber cost can contribute more than $50 \%$ of total mills' operating cost (Zuo et al. 2003). Therefore it is important to achieve the highest yields possible when salvaging lumber without sacrificing too much time or energy extracting clear material. This has been the focus of considerable research in the past.

Due to decreasing production of quality timber and lumber, many different utilizations techniques have been proposed. Rough mill yield is a major measurement of mill productivity. Lumber grade affects the productivity and operating costs of rough mills. Utilizing low-quality lumber creates difficulties due to the increased presence and concentrations of defects. Analyzing boards for optimum cutting solutions becomes more difficult and time consuming. Also, more energy is required to remove the clear material resulting in increased wear and tear on machinery. Steele et al., (1999) investigated the relationship between machine productivity and lumber grade. It was found that sawmill productivity decreased significantly when lower grades were processed. Advancements in lumber vision technologies have the potential to improve decision making and increase productivity of processing low-grade material. Buehlmann et al., (1999) investigated the potential for increasing lumber recovery by including character-marked lumber into dimension parts for the 
furniture and cabinet industries. It was found that yield increases of up to $15 \%$ could be obtained in rip-first rough mills.

Bumgardner et al., (2001) reviewed options from the past and present for improving utilization of small-diameter hardwood timber. One suggestion noted was the possibility of modifying a previously proposed method called System 6 . This was a process aimed at creating a new marketing approach to create solid hardwood panels directly from low-quality timber for use in furniture and cabinet manufacturing. This process was never widely adopted; however, portions of System 6 have been used in modified forms (Bumgardner et al. 2001). Changes in the availability of quality material as well as in technology may create new interests in this process. Some of these alterations include salvaging small pieces from lumber to improve yields and the use of finger-jointing to create longer stock which may have a variety of uses.

Lang and Hassler (2000) investigated the feasibility of finger-jointing lumber at various moisture contents to create pallet stock. Results indicated that diffuse-porous species could be finger-jointed while green to create viable products. Finger-jointing processes provided efficient end-jointing techniques and provided the necessary strength to create value-added products. 


\subsection{Finger-Jointing}

Low-quality lumber contains many defects including knots, wane, and decay limiting its use for many markets. Due to the high concentration of defects, it requires more energy to remove the clear material and results in low productivity and yields. However, by utilizing small pieces of lumber it is possible to improve yields when salvaging low-grade hardwoods (Shepley et al. 2004).

Effectively end-jointing lumber has always presented difficulties because wood cannot be bonded well, end-grain to end-grain. Many end-to-end joints such as scarf joints do not exhibit high strength values and create excessive waste. Finger-jointing has been used for more than 90 years to create usable stock by end-jointing small clear pieces of lumber (Jokerst 1981). Finger-jointing can create quality joints to create long usable stock and improve utilization of small pieces. The joint creates grooves in the end of lumber exposing side grain and provides sufficient surface area for proper gluing. Properly finger-jointed lumber can attain up to $90 \%$ of the tensile strength of clear lumber (FPL 1999).

There are two classes of finger-joints: nonstructural and structural. Nonstructural finger-joints typically utilize shorter finger lengths and blunt tips; whereas structural joints use longer fingers and narrower tips. Lumber is generally finger-jointed in two different orientations; horizontal and vertical (Jokerst 1981). Both different types offer their own advantages and disadvantages. The aesthetics of the finger-joints differs as seen in Figure 2.1. 


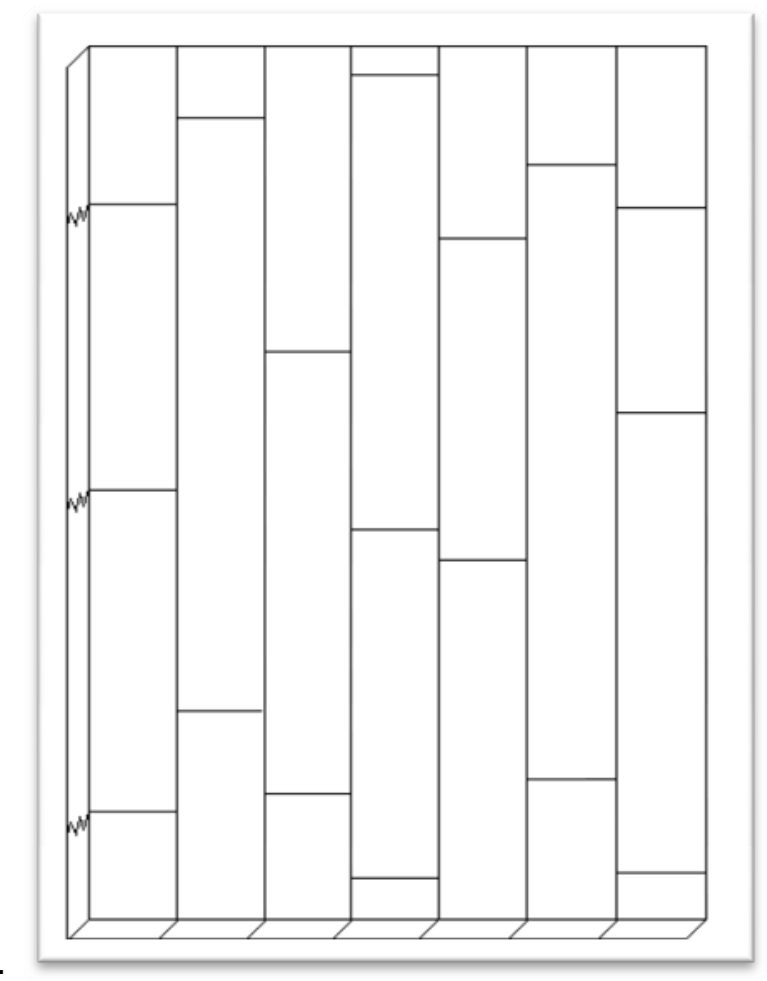

a.

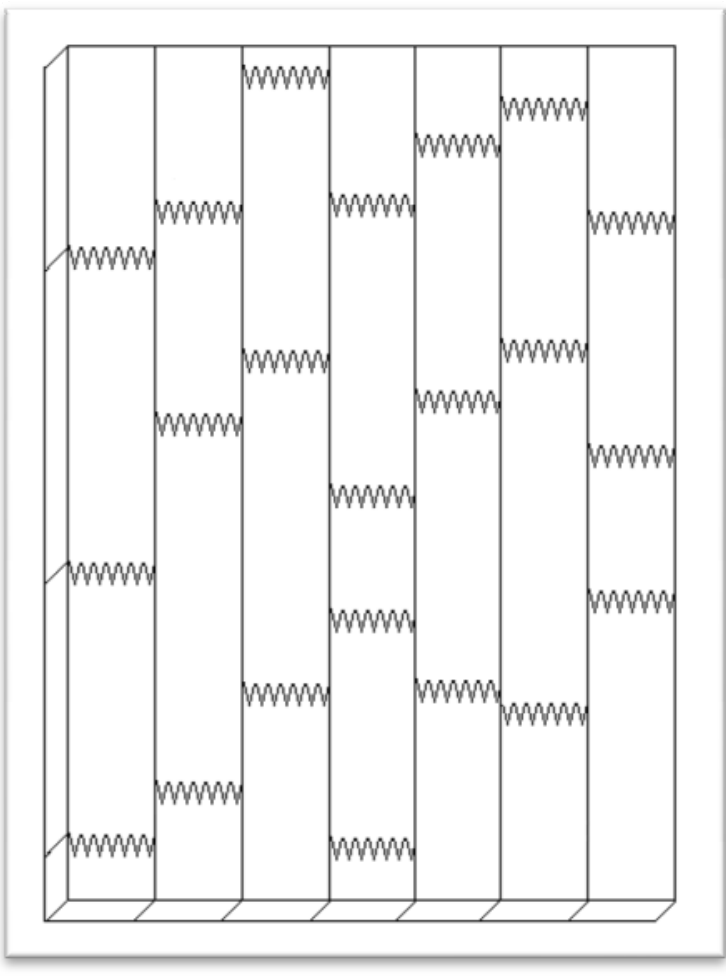

Figure 2.1 Appearance of finger-jointed, edge-glued panels. Horizontally oriented finger-joints (a) and vertically oriented finger-joints (b). 
Vertical joints are visible on the face of finger-jointed lumber which may not be desirable for some uses. However, the inclusion of these joints makes it clearly visible the product is constructed of solid wood. Both methods provide the opportunity to convert small pieces into longer, usable stock.

Nonstructural finger-joints are often used in the molding and millwork industry for trim, siding, fascia boards, and door stiles. Uses for structural applications include jointing studs and glu-lam beams as well as joining rails and window frames (Jokerst 1981). Recent interest has been expressed to create finger-jointed, edge-glued panels from small clear pieces to improve recovery of low-quality lumber. 


\section{MATERIALS AND METHODS}

\subsection{Materials}

This project investigated methods to improve lumber recovery ratios for traditional Appalachian hardwood species by using finger-jointing technologies to create value-added products from the recovered lumber. Four commonly used Appalachian hardwood species were investigated for this study:

1. black cherry (Prunus serotina)

2. soft maple (Acer rubrum)

3. red oak (Quercus rubra)

4. yellow-poplar (Liriodendron tulipifera)

Lumber used in this project was donated by two different sawmills:

Coastal Lumber located in Bruceton Mills, WV, and Allegheny Wood Products in Kingwood, WV.

All lumber was nominal 4/4 thickness and was graded No. 3A Common $(3 \mathrm{AC})$ at the respective sawmills according to the National Hardwood Lumber Association grading rules. This project consisted of three phases; each which processed $400 \mathrm{BF}$ of each species, for a total of $4,800 \mathrm{BF} 3 \mathrm{AC}$ lumber.

Lumber was dried and salvaged at WVU using the facilities located at the Division of Forestry and Natural Resources (DFNR) in Morgantown, WV. Phase I salvaged rough lumber while still green. During Phases II and III, lumber was first dried at the DFNR using a dehumidification (DH) kiln. 
Clear lumber recovered (hereafter referred to as short(s)) from the salvage operations were finger-jointed and then further processed to create value-added products. Half of the finger-jointing operations occurred at the DFNR and half were manufactured at Weinig Inc. in Mooresville, NC. Horizontally-oriented finger-joints were created at the DFNR and required the use of an industrial wood shaper and finger-joint cutter-head. After fingers were cut, a polyvinyl acetate (PVA) resin (Table 2.1) was applied and the material was joined end-to-end. A clamping system was used to apply pressure to force the joints together.

Table 2.1 Specifications of resin used for finger-jointing and edge-gluing operations.

\begin{tabular}{|l|l|}
\hline Resin Type & Cross-linked polyvinyl acetate \\
\hline Solid Content & $48 \%$ \\
\hline Viscosity & $4,000 \mathrm{cps}$ \\
\hline Calculated VOC & $5.5 \mathrm{~g} / \mathrm{L}$ \\
\hline Weight/gallon & $9.1 \mathrm{lbs}$ \\
\hline $\mathrm{pH}$ & 3.0 \\
\hline Open Assembly Time & 5 minutes \\
\hline Total Assembly Time & $10-15$ minutes \\
\hline Minimum Required Spread & Approximately 250 sq.ft/gallon \\
\hline Required Clamping Pressure & Softwoods: $100-150$ psi \\
\hline & Medium Hardwoods: $125-175 \mathrm{psi}$ \\
\cline { 2 - 2 } & Dense Hardwoods: $175-250 \mathrm{psi}$ \\
\hline
\end{tabular}

Source: http://www.titebond.com

Once the finger-joints cured, the long boards created (hereafter referred to as 'blank(s)') were surfaced on four sides to prepare for edge-gluing; a 4-head moulder was used to accomplish this task. Blanks were cut into the approximate length of finished panels. The resultant finger-jointed, surfaced, blanks prepared for edge-gluing will be referred to as staves. The appropriate numbers of staves were selected and edge-glued to achieve the desired width of finished panel. 
Edge-gluing was accomplished using stackable panel clamps. After the resin had fully cured, the panels were sent through a planer to achieve the desired uniform thickness. Finally, the panels were ripped and trimmed to their final dimensions using a table saw.

After panels were formed they were put in an environmental chamber and subjected to increased humidity. Dimensional stability was investigated by measuring the panels before and after exposure to environmental changes. Warp measurements were taken on a flat table using a calibrated wedge and metal ruler.

Mechanical tests were performed on finger-jointed samples to determine the mechanical properties of the finished products. Samples were placed in a conditioning chamber before testing to achieve an EMC of $12 \%$. Three-point static bending tests were performed using a MTS-810 Universal Servo-Hydraulic Testing machine with Instron data acquisition system.

\subsection{Methods}

\subsubsection{Acquiring and Drying Lumber}

This project comprised three phases. Each phase of the project investigated $400 \mathrm{BF}$ of each of the four previously noted species, for a total of 4,800 BF processed (4 species $\times 3$ phases $\times 400 \mathrm{BF}=4,800 \mathrm{BF}$ ). Lumber was acquired soon after it had been sawed to prevent a loss in MC. 
All lumber was salvaged while green during Phase I of the project (salvage methods are described in the next section). $400 \mathrm{BF}$ of each species was acquired and subsequently salvaged to remove defects. The resultant material was then stored for future use.

Phase II and Phase III called for lumber be dried to approximately $14 \%$ $M C$ by weight before salvaging. The lumber was dried using a dehumidification (DH) kiln located at the DFNR. Lumber was stacked and stickered according to the procedures described in the Dry Kiln Operator's Manual (Simpson 1991). Approximately $1,800 \mathrm{lbs}\left(40 \mathrm{lbs} / \mathrm{ft}^{2}\right)$ of top-weight was uniformly applied to aid in the prevention of drying defects. Species were dried separately based on kiln schedules provided by the manufacturer of the $\mathrm{DH}$ kiln. After lumber reached the desired MC, the charge was removed and sent to the wood shop to be salvaged. A new charge of $400 \mathrm{BF}$ was then dried while the first charge was salvaged.

Moisture content of lumber throughout the drying process was determined in accordance with ASTM standard 4442-06. Also, MC was approximated using a Delmhorst electronic resistance moisture meter.

\subsubsection{Salvaging Methods}

Rough lumber was processed to remove defects and recover the maximum volume of clear, material. A small minimum cutting-size was chosen to 
first establish how much useable wood was contained in the rough lumber.

Defect-free material was extracted, measured, and stored.

It was important to remove the entire defect and surrounding abnormal wood in order to ensure suitable wood existed to provide for a quality finger-joint.

Defects identified for removal were chosen based on the Wood Component Manufacturers Association's Rules and Specifications for Dimension and Woodwork (WCMA 2007) and included:

- all knots larger than $1 / 8$,

- decay,

- excessive warp,

- end splits,

- pith,

- surface checks,

- wane,

- and worm holes.

Lumber was salvaged at the woodshop located in the DFNR. An industrial chop saw and straight-line rip saw were used to process the material. Each board was inspected and a cutting pattern was drawn on the board based on the location of defects (Figure 3.1).

Figure 3.1 Example of cutting pattern used to salvage rough lumber. 
The boards were either cross-cut or ripped first to remove defects based on placement and concentrations of defects. Additional salvaging processes were performed to remove all usable material from the rough lumber.

For Phase I, the minimum-size piece (cutting-size) removed from the lumber was 1 " width by 6 " length. This cutting size was used to determine the maximum volume of clear, defect-free material contained in the lumber. All four species were salvaged and the lumber was stored for measurement and analysis.

During Phase II and III the minimum cutting size was altered to 1.5 " width by 12 " length. This length was determined to be the minimum length necessary in order to be compatible with finger-jointing machinery used later in the project. All shorts recovered were measured to obtain width and length to the nearest 1/8". The material was then further processed to prepare for finger-jointing operations.

The shorts measured up to this point consisted of random widths and lengths. Finger-jointing operations require lumber to be of uniform widths in order to process it. Also, different finger-jointing machines handle different dimensions of materials. Therefore the material had to be processed into uniform-widths and meet all other size constraints dictated by the two fingerjointing processes used in the study.

The machinery used to create vertically finger-jointed lumber was capable of utilizing material from 6"-28" in length and could joint widths from 1.5 " to $6 "$ ". Horizontally finger-jointed lumber produced at the DFNR required shorts to be at 
least 12 " long. Therefore, a 1.5 " width by 12 " length board was the minimum size that was used for finger-jointing operations.

Material that was larger than finger-jointing machine capabilities was reripped or cross-cut into appropriate sizes; shorts longer than 28" were cross-cut and widths greater than 6" were re-ripped into smaller dimensions.

The material was then ripped into several different width-classes (Wt.C.). Nine widths were selected in an attempt to maximize the recovery of the random sized shorts. These widths were selected based on the width-distributions of shorts measured during the three salvaging phases (the methods for selecting width-classes is discussed further in section 4.1). The nine width-classes selected were:

$$
\text { 1.5", 2.0", 2.5", 2.75", 3.0", 3.25", 3.5", 4.0", and 4.5". }
$$

All of the shorts were re-ripped to fit the nearest lower width-class (i.e. $2.625 " \rightarrow 2.50 ", 3.875 " \rightarrow 3.5$ "). Specimens wider than 5 " were re-ripped in a way to maximize recovery (i.e. $5.0 " \rightarrow 2.0$ " Wt.C. and 2.75 " Wt.C. with 0.25 " lost in saw kerf; as opposed to $5.0 " \rightarrow 4.5$ " Wt.C. with 0.5 " waste). All newly salvaged shorts were then re-measured and stored for future use. 


\subsubsection{Finger-jointing Operations}

A portion of the shorts salvaged from the project were finger-jointed to create value-added products. Half of the finger-jointing processes were conducted at the DFNR, while the second half was processed in at Michael Wienig, Inc. in North Carolina. Figure 3.2 shows the finger-joint geometry of the two different cutter-heads.

a.

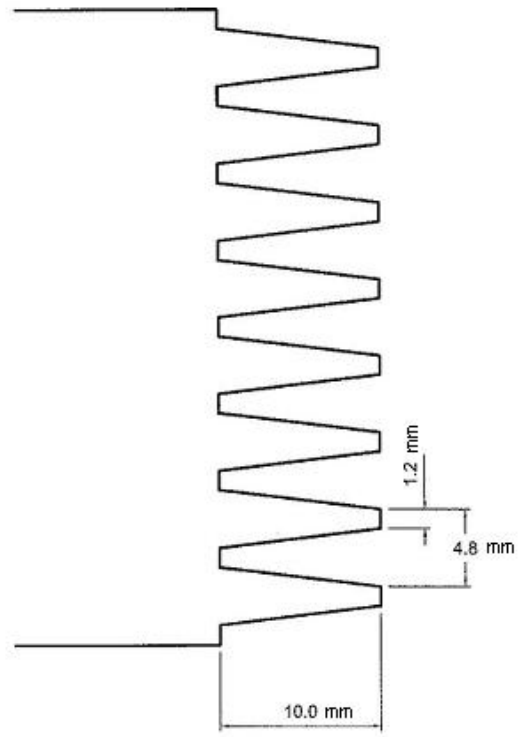

b.

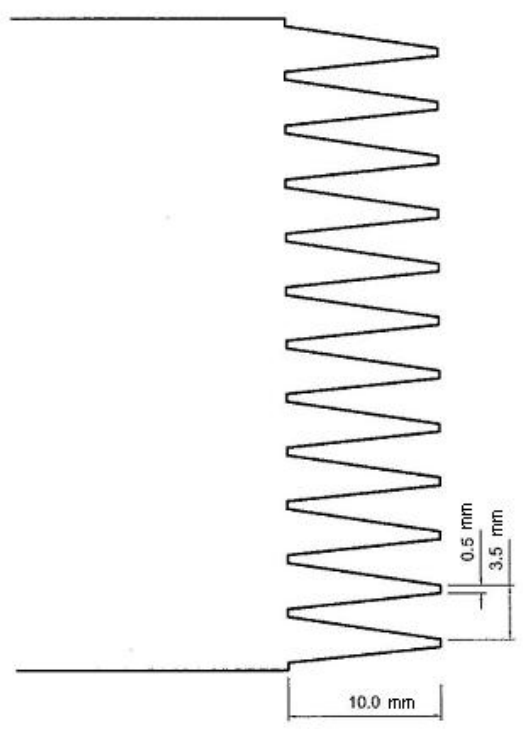

Figure 3.2 Description of cutter-head geometry for horizontal (a) and vertical (b) finger-joints.

Horizontal finger-joints were manufactured at the DFNR lab at Percival Hall in Morgantown, WV. An insert-type finger-joint cutter was purchased and mounted on a single spindle shaper. The machine used a $5 \mathrm{HP}$ motor and had a spindle rotation of 7,200 revolutions per minute (rpm). The geometry of the finger-joint cutter-head is described in Figure 3.2. 
The shorts were clamped down to a movable guide ensuring the ends of were aligned 90 degrees to the cutter-head (Figure 3.3). The guide was manually moved across the cutter-head creating the fingers in the ends of the specimens.

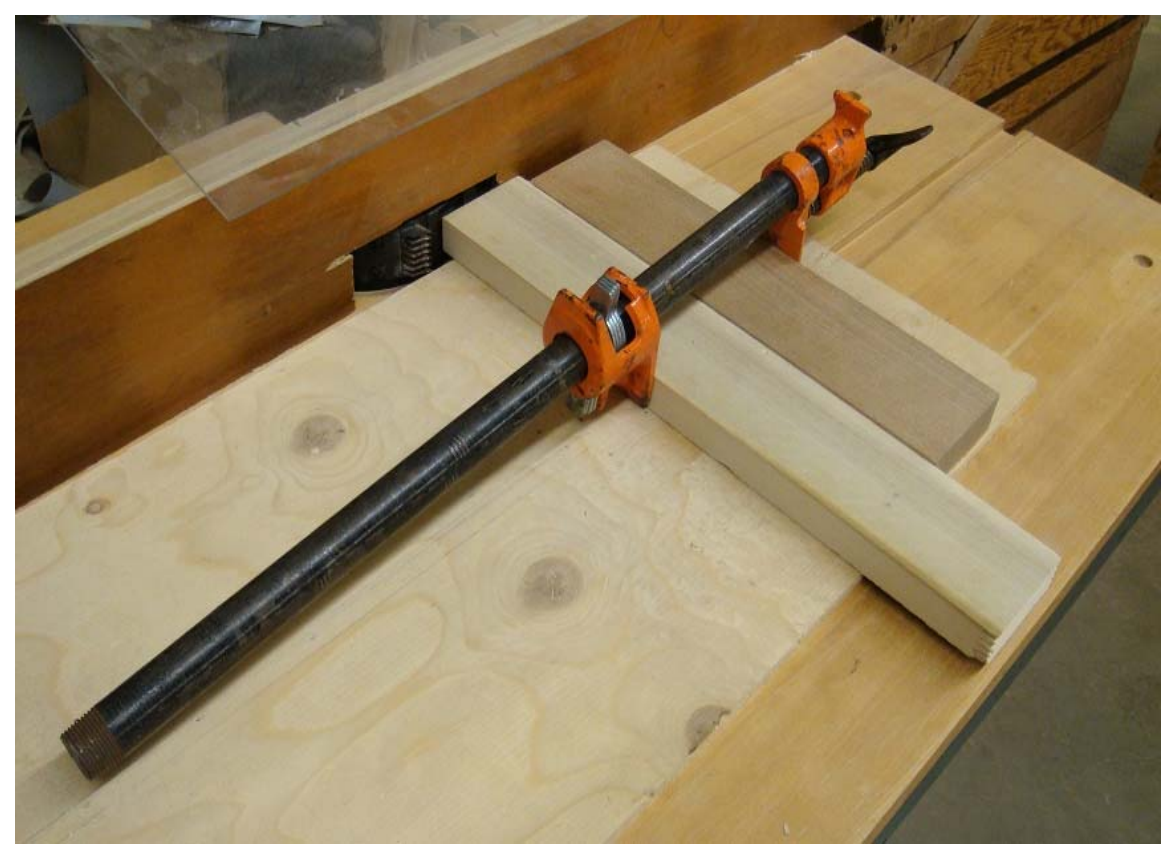

Figure 3.3 Shaper set-up used for manufacturing horizontal finger-joints.

The cutter-head was set up to cut one end of a short, and was then adjusted to cut the opposite end to create a good fitting end joint.

The feed-rate of the guide had to be relatively slow otherwise tearout could occur on the side of the specimen (Figure 3.4). 


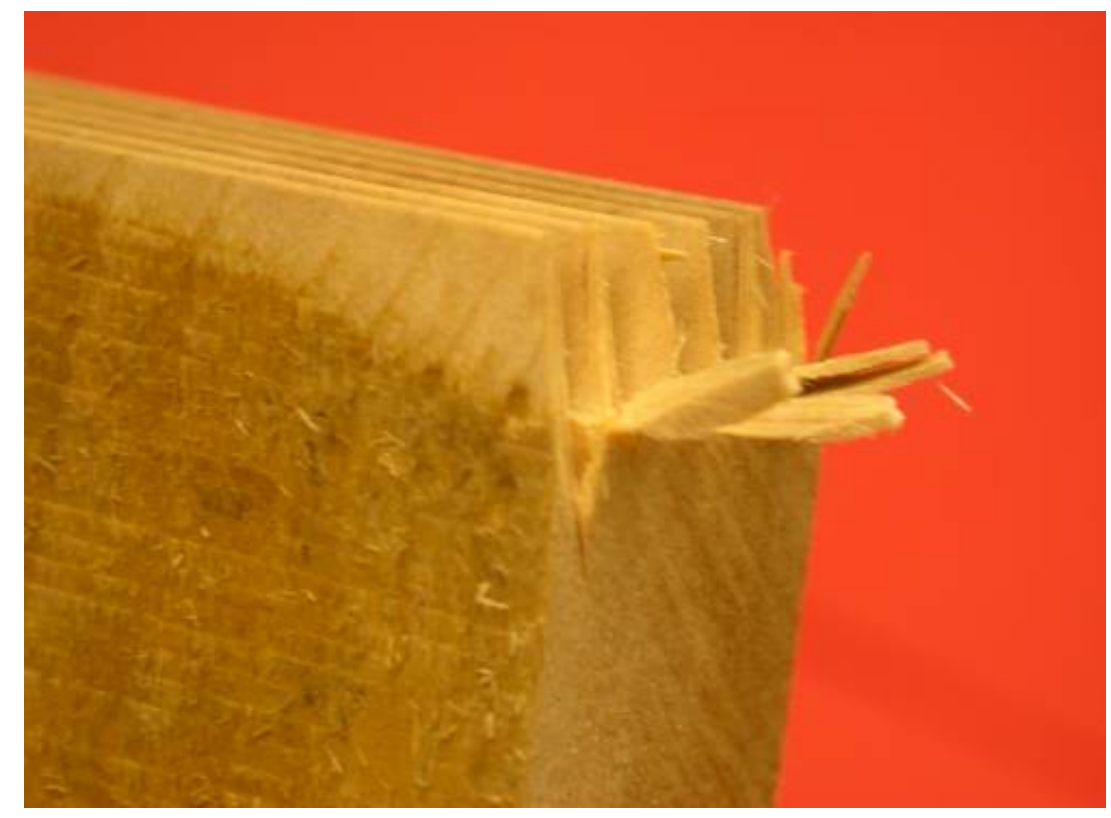

Figure 3.4 Tearout in horizontal finger-joint caused by high feed-rate.

This problem was most prevalent in the red oak specimens, most likely due to the anatomy of the species; however, it occurred among all species jointed. When this occurred it was necessary to cut off the fingers and remanufacture the finger-joint.

Some warping occurred in the specimens between the time the specimens were salvaged and the time they were finger-jointed. Due to the tolerances of finger-jointing machinery, warp can create difficulties in processing. When all sides of the specimen were not square, they had a tendency to slip and rotate when moved across the cutter-head (while clamped to the moveable guide). This resulted in fingers that were too thin and were unable to ensure a quality joint. In these cases the unsatisfactory fingers were cut off and the specimens were jointed again. 
Specimens which were twisted or bowed also created difficulties.

Specimens longer than approximately 18 " containing either of these forms of warp were cross-cut into more manageable pieces. Warped material that was attempted to be finger-jointed often resulted in fingers being cut at an angle not parallel to the plane of the board (Figure 3.5). This resulted in 'slanted' joints that if connected with other finger-jointed material created twisted blanks that were not suitable for edge-gluing.

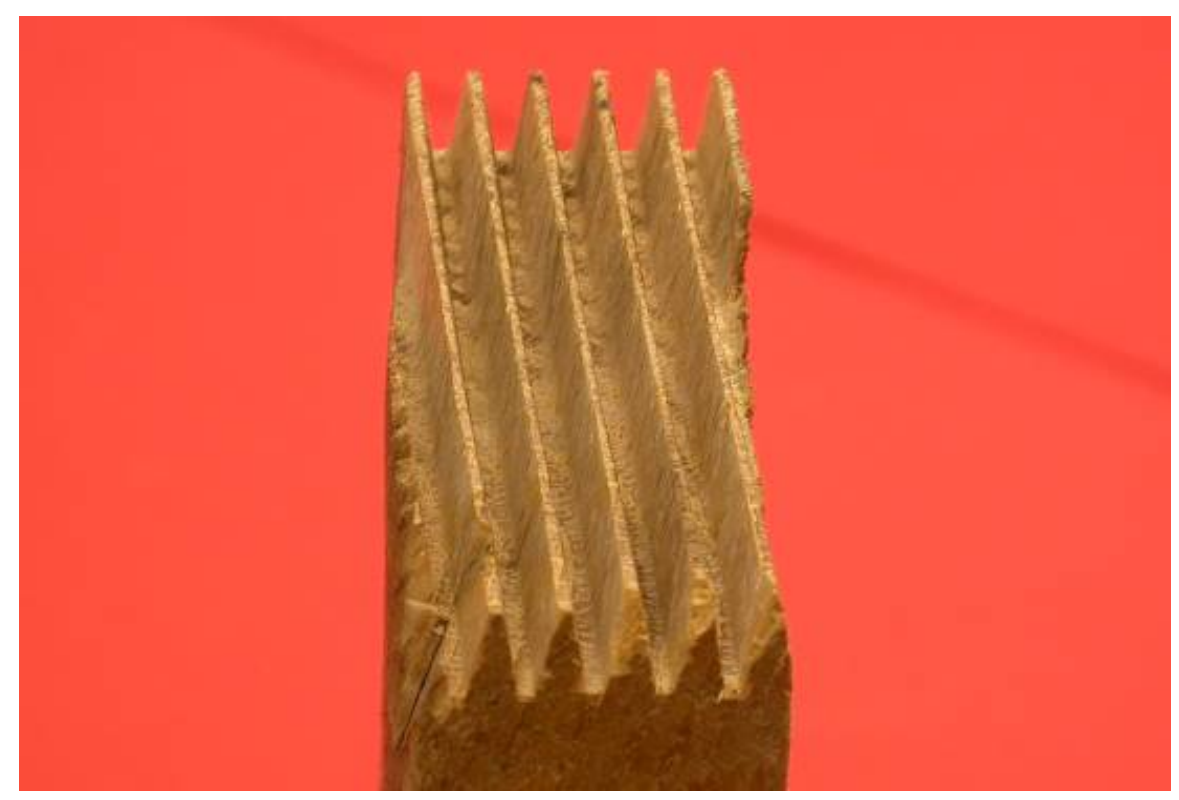

Figure 3.5 Specimen with slanted fingers produced from warped shorts.

After finger-joints were created, the shorts were immediately transferred to be glued and pressed into approximately $7 \mathrm{ft}$ long sections (blanks). Sufficient resin was manually applied using a brush to evenly cover the fingers. Shorts were matched end-to-end to and pressed into $7 \mathrm{ft}$ blanks using a screw-driven clamping device (Figure 3.6). A small amount of pressure was applied to the top 
of the blanks to prevent the shorts from buckling upwards. The shorts were glued using an activated polyvinyl acetate (PVA) resin.

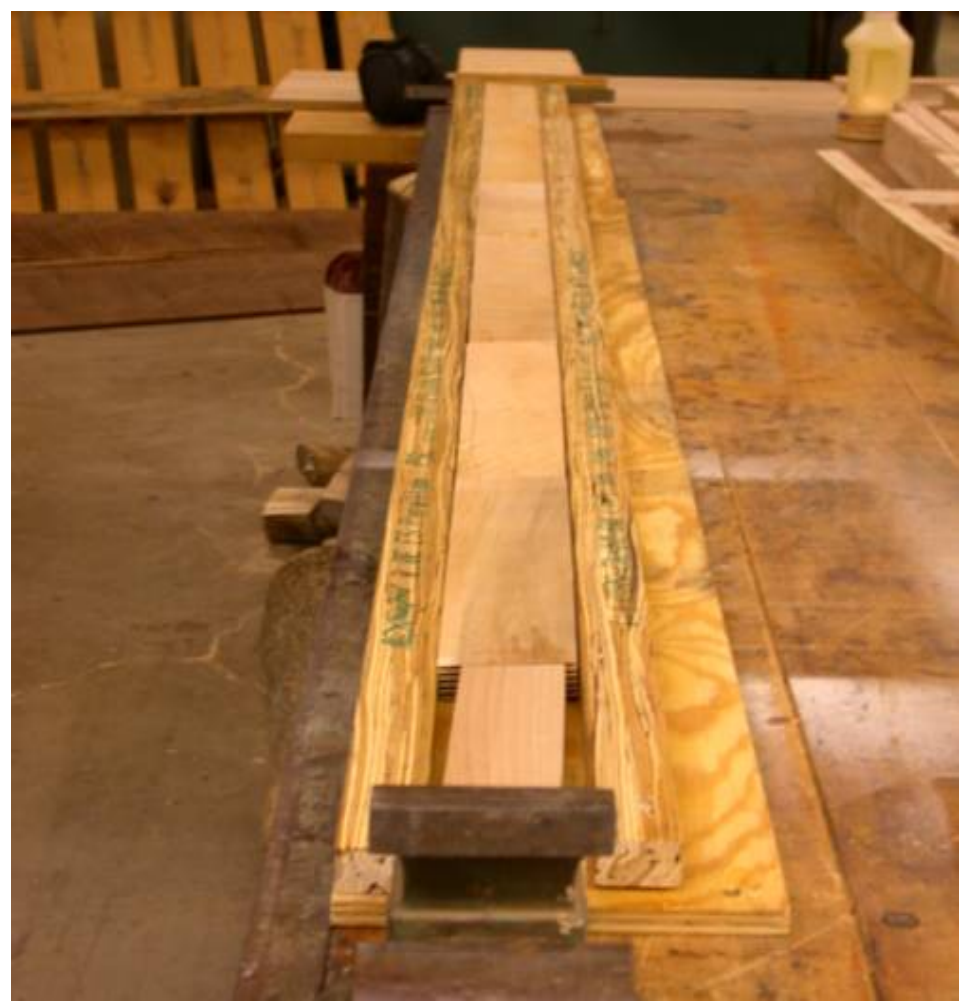

Figure 3.6 Press used for manufacturing finger-jointed lumber at DOF.

Continuous pressure was applied for 20 minutes and the blanks were then removed from the clamp and allowed to cure completely.

Vertical finger-joints were manufactured at the Michael Weinig, Inc. North American headquarters located in Mooresville, NC. A Grecon Profijoint D-110 finger-jointer was used to produce the joints (Figure 3.7). 


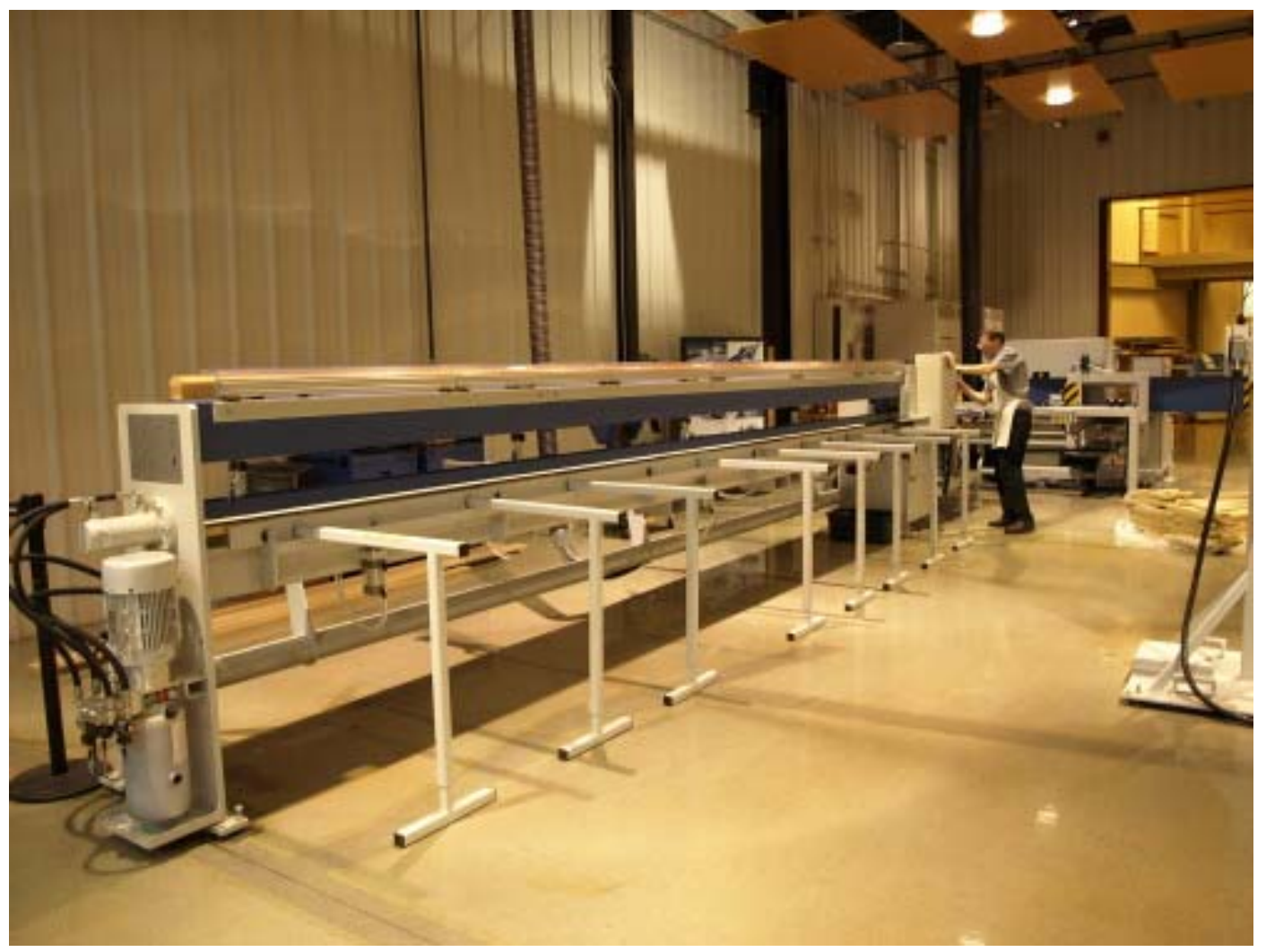

Figure 3.7 Grecon Profijoint machinery and press used to produce vertical finger-joints.

The machine used a 30HP motor with a six-inch vertical cutter-head to manufacture finger-joints. The fingers were 10-mm deep with a tip-to-tip span of 3.5-mm (Figure 3.2).

One worker loaded the shorts into the machine and performed the cutting of the fingers. Meanwhile another person received the freshly cut and glued shorts and arranged them to be pressed. A 20 -foot capacity press connected to the machine was used to press the shorts together. The pressure applied was adjusted according to the cross-section dimensions of the lumber to provide the proper amount of force. 
The material was processed one width-class at a time. The shorts were loaded into the machine which cut the fingers and then applied glue using a glue comb with pump and tank. An activated polyvinyl acetate (PVA) resin was used. The press applied continuous force for approximately 15 seconds and then discharged the blanks in lengths of 16 feet. After curing for approximately 15 minutes, the blanks could be handled without compromising the strength of the finger-joints. All material was then returned to the DFNR for further processing.

\subsubsection{Panel Production}

After the shorts were finger-jointed and glued to form blanks, either at the DFNR or at Weinig, Inc., they needed to be surfaced in preparation for edgegluing into panels. Blanks were surfaced on four sides using a 4-head moulder (Figure 3.8). 


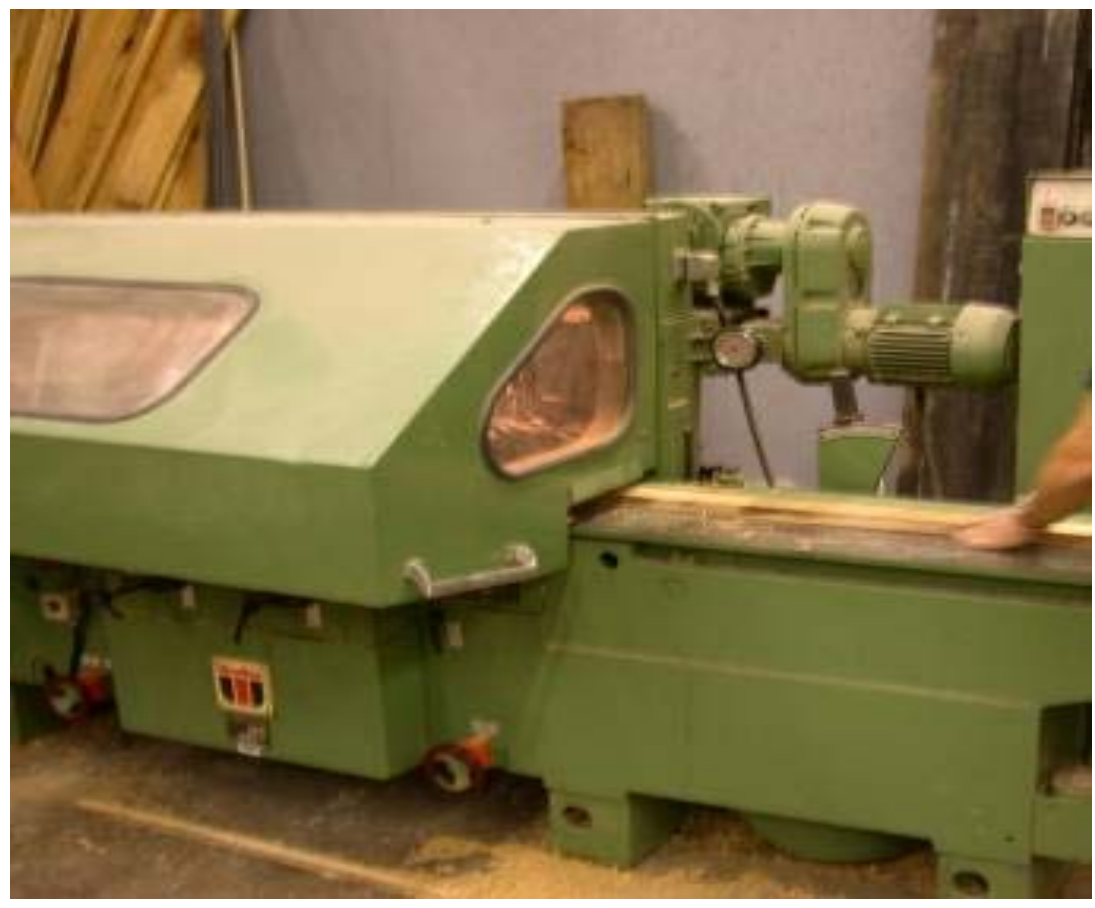

Figure 3.8 Four-head moulder used to prepare blanks for edge-gluing.

The objective of this step was to convert the blanks into square stock so they could be properly edge-glued; while removing as little material possible during the process. The moulder was set-up to remove 0.125 " of material from each edge of blanks. The lower cutter-head on the machine removed 0.087 " and the top cutter was set so that the final thickness of the material would be approximately 0.875 .

After the blanks were moulded, they were cut into the approximate length of the finished panels. These ready-to-edge-glue pieces of lumber are referred to as staves. The appropriate numbers of staves were edge-glued to create the desired width of the panels. Stackable panel clamps (Figure 3.9) were used to provide proper pressure to edge-glue the material. A small paint roller was used to apply a consistent amount of PVA glue to the edges of staves. 


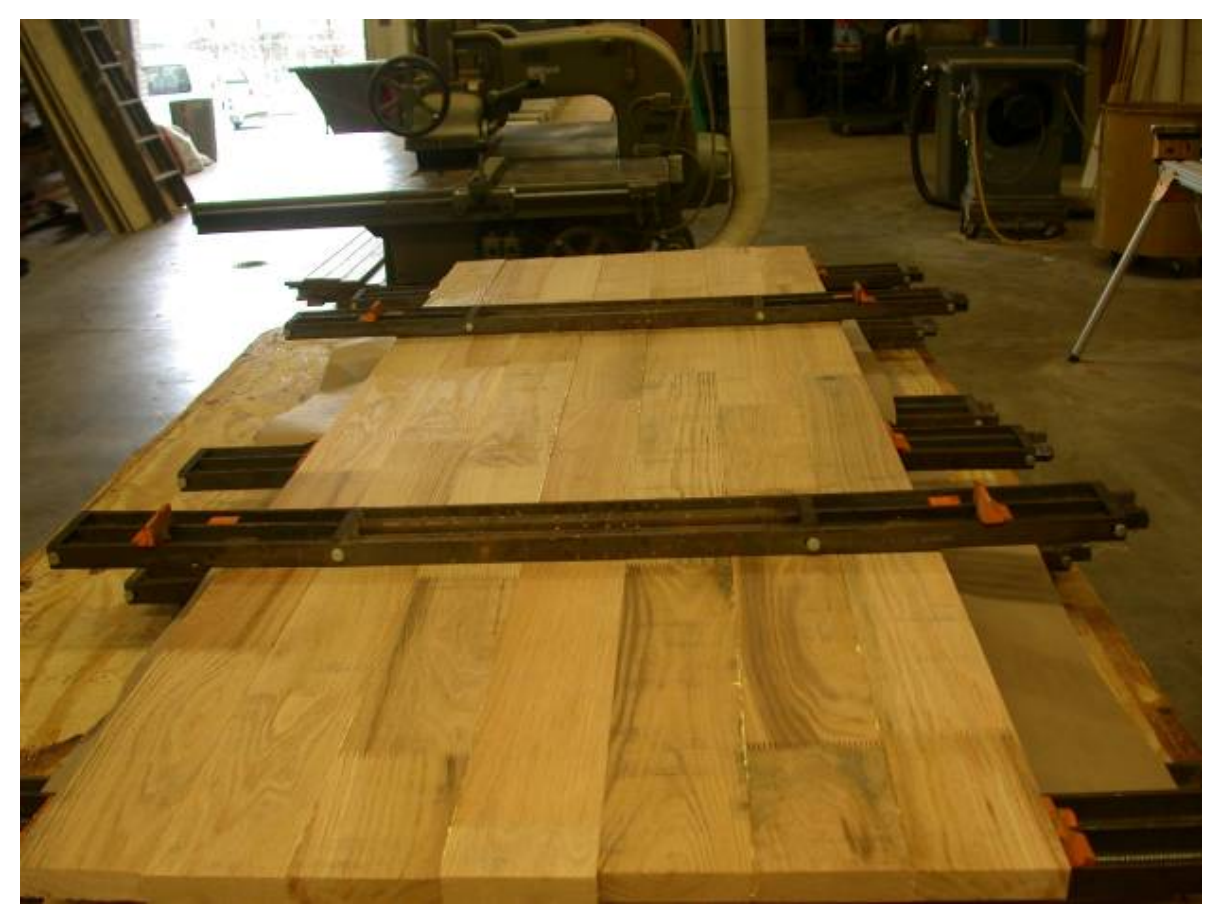

Figure 3.9 Production of edge-glued panels using panel clamps.

After the curing, the panels were fed through a surface planer to achieve a final thickness of $3 / 4$. Finally, the panels were trimmed to their final width and length of 26 " and 38 " respectively. Panels were measured and stored for mechanical and dimensional stability testing.

\subsubsection{Panel Warp Determination}

Dimensional stability of the panels was investigated by measuring certain forms of warp before and after exposure to elevated humidity conditions. Bow and cup were the two forms of warp measured. 
Bow is defined as a deviation from lengthwise flatness in a board. Cup is defined as a deviation from flatness across the width of the board. Both initial measurements were taken immediately after the panels were trimmed to their final dimensions. The ambient conditions were 70 degrees Fahrenheit and approximately $55 \%$ relative humidity, equivalent to approximately $10 \%$ EMC. Panels were measured on a flat table using a calibrated wedge and metal ruler to the nearest 1/20" (Figure 3.10).

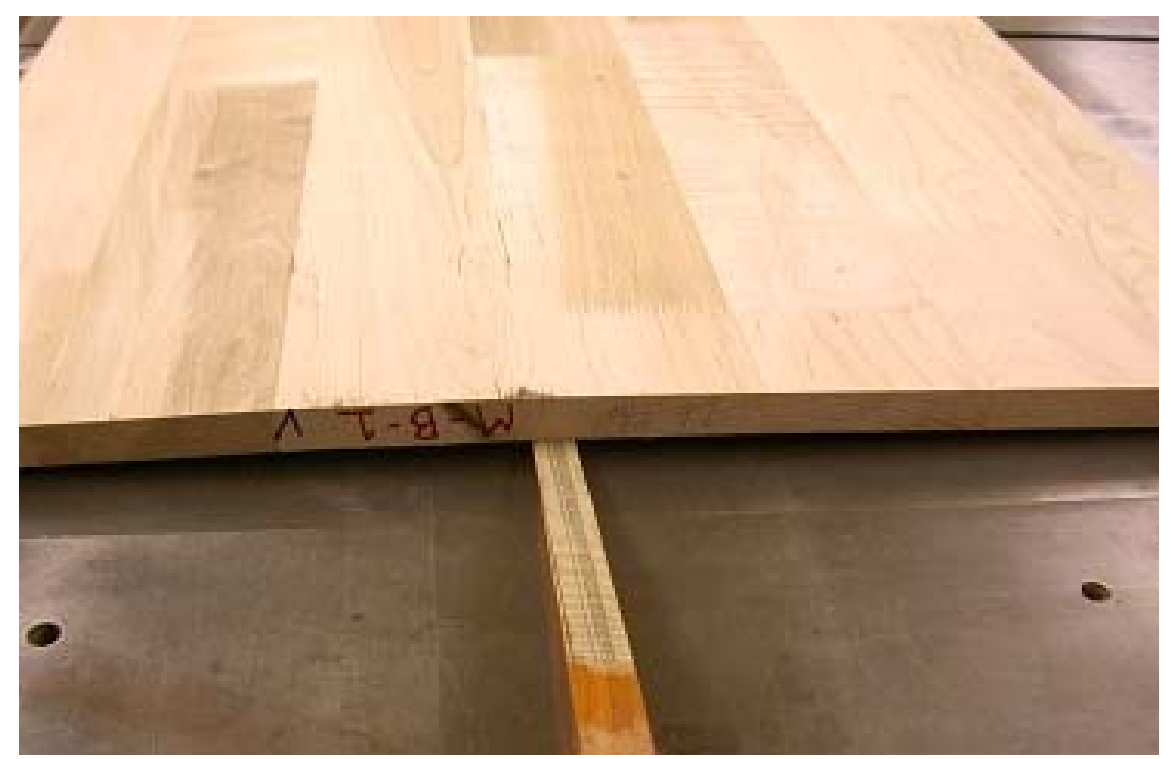

Figure 3.10 Measurement of warp (cup) using a calibrated wedge.

The panels were then subjected to 30 days of elevated humidity and then allowed to equilibrate to their original EMC. Measurements were re-taken and pre and post warp measurements were compared. Figure 3.11 represents the environmental conditions the panels were subjected to. 


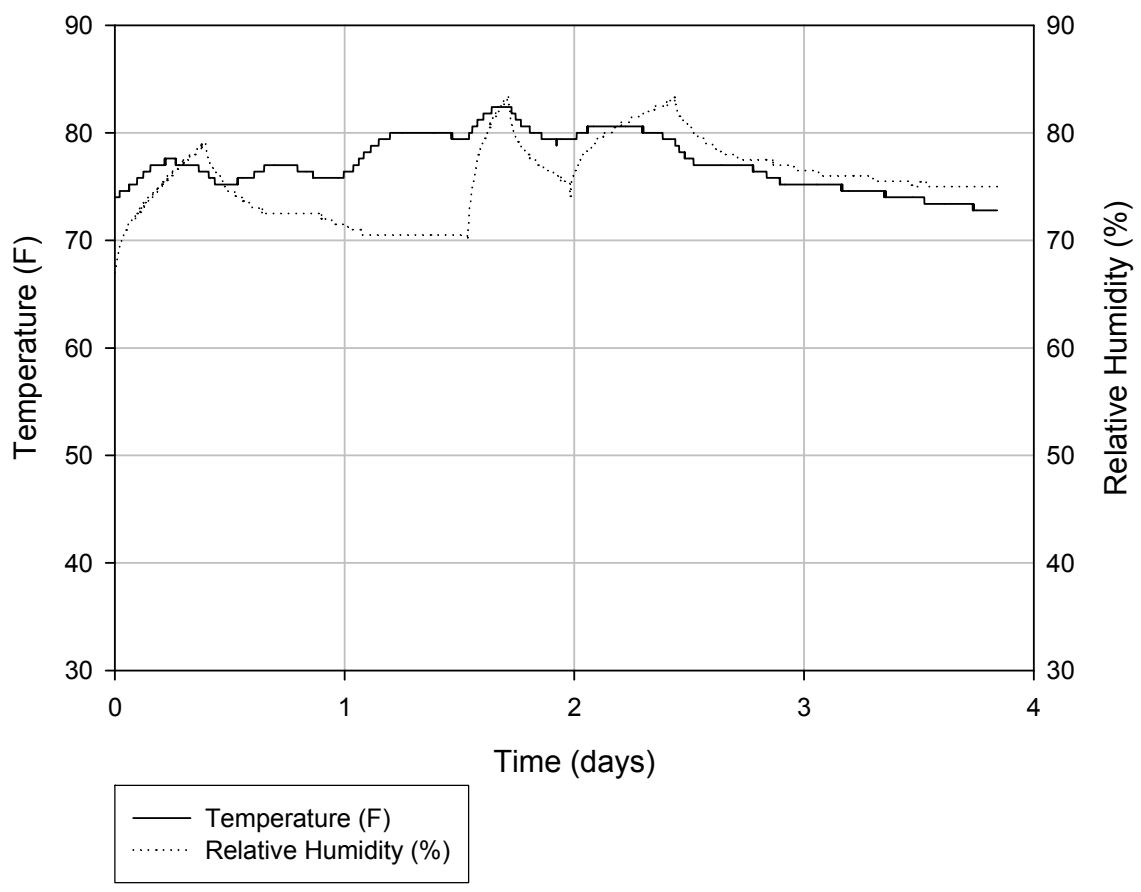

Figure 3.11 Environmental conditions used for panel warp determination.

\subsubsection{Mechanical Testing}

The mechanical properties of the panels were evaluated by testing samples in bending to determine modulus of elasticity (MOE) and modulus of rupture (MOR).

Samples were selected from the species finger-jointed (cherry, maple, and red oak) and machined into tests specimens. Ten samples from each species and finger-joint type (horizontal and vertical) were tested. Also, a control group was machined from solid wood to compare to the finger-jointed specimens. Three-point static bending tests were performed to evaluate MOR and MOE in 
bending. A modified ASTM 1037 procedure was followed to test the specimens. Due to the intended end-use of the product as a panel material, this method was used to evaluate the mechanical behavior in panel flexure. Test specimens were machined to the following dimensions: 2.75 " width by 20 " length by 0.75 "

thickness. Actual dimensions were measured using a digital caliper with a 0.01$\mathrm{mm}$ resolution. Figure 3.12 shows the testing set up used. Specimens were tested to failure using a Servo-Hydraulic MTS testing machine with a 20,000 lbs load cell operated under displacement control.

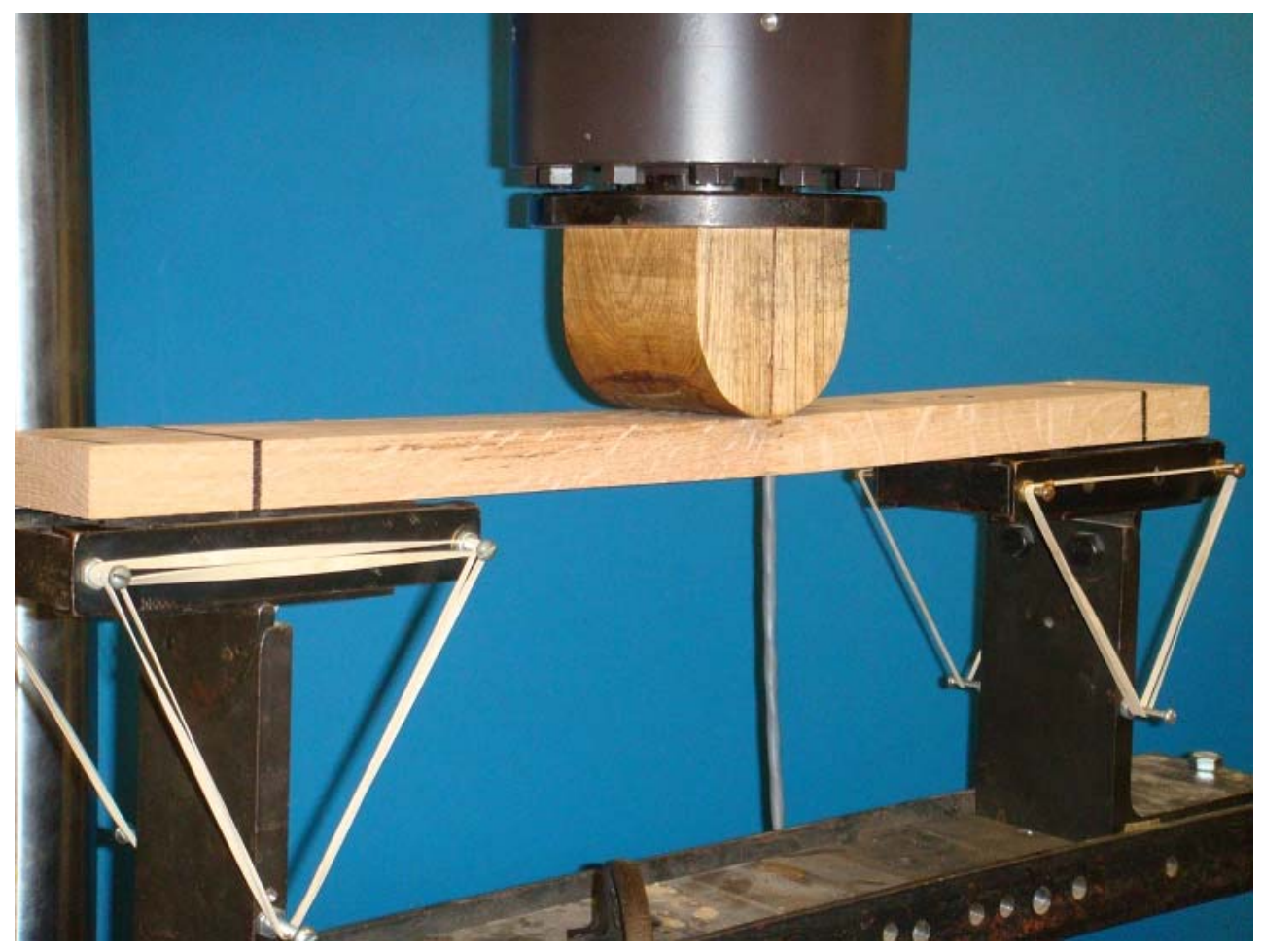

Figure 3.12 Determination of MOE and MOR of horizontally finger-jointed red oak test specimen by static three-point bending. 
The load was applied directly perpendicular to the finger-joint in the test specimen. Speed of testing was determined in accordance with ASTM 1037-99 using the following equation:

$$
N=\frac{0.005\left(L^{2}\right)}{6(t)}
$$

Where:

$N=$ speed of test $(\mathrm{in} / \mathrm{min})$,

$L=$ length of span (in),

$t=$ thickness $($ in $)$.

The load was applied continuously at $0.36 \mathrm{in} / \mathrm{min}$. until failure occurred. A total of 60 test specimens were prepared and tested. Load-displacement data pairs were collected during the tests by an Instron data acquisition program. Using the data collected, MOE and MOR were determined using the equations found below:

$$
I_{X}=\frac{b h^{3}}{12}
$$

Where:

$I_{X}=$ moment of inertia $\left(\right.$ in $\left.^{4}\right)$,

$b=$ width of specimen (in),

$h=$ height of specimen (in). 


$$
E=\frac{F L^{3}}{48 I_{x} \Delta}
$$

Where:

$E=$ modulus of elasticity (psi),

$F=$ load $(\mathrm{lbs})$,

$L=$ testing span (in),

$I_{x}=$ moment of inertia $\left(\right.$ in $\left.^{4}\right)$,

$\Delta=$ deflection (in).

Modulus of rupture was determined by first calculating the maximum moment and section modulus of the test specimens. The formulas necessary for calculation are as follows:

$$
M_{\max }=\frac{F_{\max } L}{4}
$$

Where:

$M_{\max }=$ maximum moment (in-lbs),

$F_{\max }=$ maximum force $(\mathrm{lbs})$,

$L=$ length of span (in). 


$$
S_{x}=\frac{b h^{2}}{6}
$$

Where:

$S_{x}=$ section modulus $\left(\mathrm{in}^{3}\right)$,

$b=$ average width of specimen (in),

$h=$ average height of specimen (in).

$$
M O R=\frac{M_{\max }}{S_{x}}
$$

Where:

$M O R=$ modulus of rupture $(\mathrm{psi})$,

$M_{\max }=$ maximum moment (in-lbs),

$S_{x}=$ section modulus $\left(\mathrm{in}^{3}\right)$. 


\subsubsection{Statistical Methods}

Different statistical procedures were used to analyze the data obtained throughout this project. The most suitable comparison method was chosen for each case. Mechanical properties were compared using one-way ANOVA and when necessary, a Kruskal-Wallis One way Analysis of Variance on Ranks test was used, followed by a Multiple Comparison Procedure to identify the groups that differed from others, in this case Dunn's Method was used.

SigmaStat ${ }$ software was used to perform statistical tests on the data. For the comparison of size distributions of the clear material, One Way ANOVA was used. However, as expected, the data was not normally distributed because it consisted of width and lengths with minimum requirements and therefore had a right-skewed distribution. Non-parametric data analysis was used in these cases. The Kruskal-Wallis ANOVA on Ranks was used. This test is used when samples are drawn from non-normal populations or when there are unequal variances. This test is essentially the same as a Mann-Whitney Rank Sum Test except there are more than two experimental groups. The null hypothesis was that there was no difference in the distribution of the values between different groups. After establishing that differences were present, the software automatically performed a Multiple Comparison Procedure to identify which groups differed. Specific procedures used are further described in the results section. 


\section{RESULTS AND DISCUSSION}

\subsection{Size Distributions of Salvaged Material}

During this project, a total of $4,800 \mathrm{BF}$ of $4 / 4$ thickness, No. $3 \mathrm{AC}$ lumber was acquired and salvaged. Rough lumber was measured upon arrival to the DFNR; approximately 1,000 individual boards were used. The summary statistics of the dimensions of this lumber may be seen in Table 4.1.

Table 4.1 Descriptive statistics of rough lumber salvaged.

\begin{tabular}{ccccccc}
\hline \hline Species & $\begin{array}{c}\text { No. of } \\
\text { boards }\end{array}$ & $\begin{array}{c}\text { Volume } \\
\text { (BF) }\end{array}$ & $\begin{array}{c}\text { Mean width } \\
\text { (in.) }\end{array}$ & $\begin{array}{c}\text { Std. } \\
\text { Dev. }\end{array}$ & $\begin{array}{c}\text { Mean } \\
\text { length (in.) }\end{array}$ & $\begin{array}{c}\text { Std. } \\
\text { Dev. }\end{array}$ \\
\hline \hline Cherry & 257 & 1202 & 6.0 & 3.70 & 108.8 & 30.33 \\
Maple & 223 & 1203 & 6.2 & 1.80 & 124.4 & 23.40 \\
Red Oak & 273 & 1202 & 5.6 & 1.97 & 111.4 & 18.33 \\
Yellow-poplar & 237 & 1201 & 6.8 & 1.19 & 107.4 & 20.33 \\
\hline \hline
\end{tabular}

1. standard deviation

The average width of cherry, maple, and oak boards was approximately 6 inches. Yellow-poplar boards had a larger mean, close to 7 inches. Statistical tests were performed to determine if sizes of input lumber were significantly different among species. One-way ANOVA was performed to determine if significant differences existed in the mean width or length of boards by species. Results indicated that yellow-poplar lumber was significantly wider than the other three species. Mean lengths were analyzed and found that maple lumber was significantly longer than 
cherry, red oak, and yellow-poplar. Results of the one-way ANOVA are located in the Appendices. This information was used to compare the dimensions of rough lumber to the dimensions of clear material and may be useful in determining a relationship between the size of rough lumber and size of the clear shorts that are salvaged from it.

Rough boards were salvaged to remove the largest area of clear, useable wood possible based on the finger-jointing machine size-constraints discussed in the methods section. This resulted in many random-size pieces of lumber. The width and length of the pieces were measured to the nearest $1 / 8$ inch and analyzed. Basic summary statistics for all three phases combined were calculated and are reported in Table 4.2.

Table 4.2 Descriptive statistics of clear material.

\begin{tabular}{ccccccc}
\hline \hline Species & $\mathrm{n}^{1}$ & Yield (\%) & $\begin{array}{c}\text { Mean width } \\
\text { (in.) }\end{array}$ & $\begin{array}{c}\text { Std. } \\
\text { Dev. }\end{array}$ & $\begin{array}{c}\text { Mean } \\
\text { length (in.) }\end{array}$ & $\begin{array}{c}\text { Std. } \\
\text { Dev. }\end{array}$ \\
\hline \hline Cherry & 1026 & 41.0 & 2.9 & 1.04 & 23.8 & 8.76 \\
Maple & 1039 & 40.3 & 3.4 & 1.25 & 23.1 & 12.10 \\
Red Oak & 1020 & 45.7 & 3.4 & 1.40 & 23.5 & 16.04 \\
Yellow-poplar & 1458 & 49.7 & 2.6 & 0.82 & 21.0 & 9.96 \\
\hline \hline
\end{tabular}

1- sample size

${ }^{2}$ - standard deviation

Maple and oak species had the largest mean width of the four species and also had the highest standard deviations. Yellow-poplar exhibited the narrowest mean width and the lowest standard deviation. Yellow-poplar also produced the shortest mean length of the four species. The data indicates that yellow-poplar 
lumber yields shorter and narrower pieces than the other three species. The lengths of pieces were approximately 23 inches for cherry, maple and oak and 21 inches for yellow-poplar. Red oak lengths had the highest standard deviation of the species at 16 inches. These size distributions were analyzed using one-way ANOVA to determine if statistically significant differences occur among species. As described in the methods section, because the data was not normal, nonparametric statistical procedures were used to compare the data.

Using the raw data collected from the measured shorts, histograms were created to represent the width and length distributions of the shorts by species (Figure 4.1). 

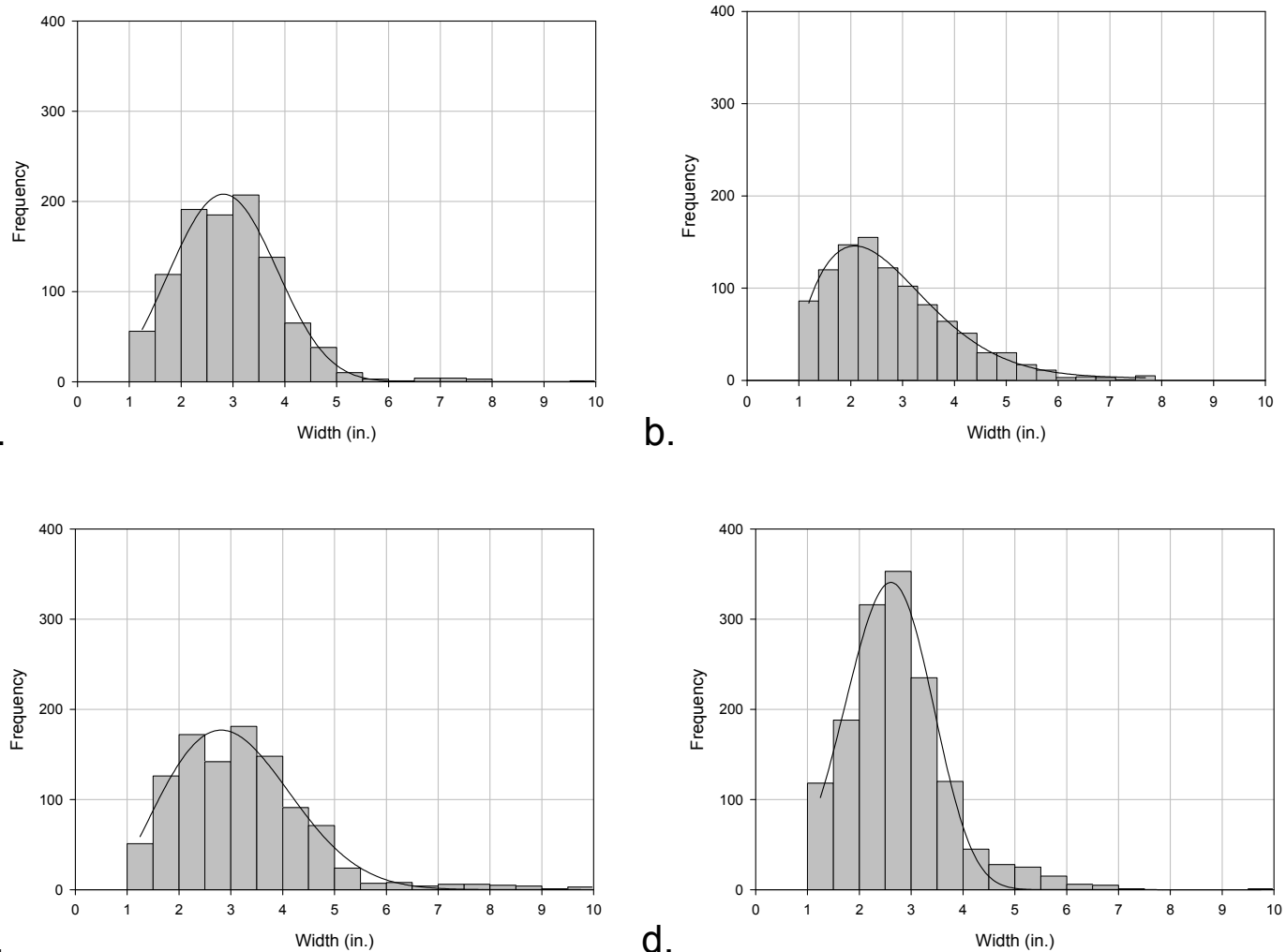

Figure 4.1 Width distributions of salvaged shorts for all phases combined for cherry (a), maple (b), red oak (c), and yellow-poplar (d).

Probability density curves were fitted to the histograms to represent the type of distributions among widths. All curves were right-skewed and had long right tails. This is due to the fact that a minimum width of one inch was necessary. This resulted in a Weibull distribution as opposed to a normal distribution. However, differences in distributions are noticeable between species which can be of importance. Cherry (Fig. 4.1a) and red oak (Fig. 4.1c) pieces were distributed very similarly and appear to be more evenly distributed across the widths as compared to maple and yellow-poplar. Yellow-poplar 
pieces were more heavily concentrated resulting in a high peak near 2.5 inches. The distribution of maple pieces was highly right-skewed. Using this data can help to determine what widths the lumber should be ripped into to maximize recovery. For instance, because cherry and red oak pieces are distributed more evenly, more width classes should be utilized to prevent excess waste. For yellow-poplar however, pieces are more concentrated around a narrower set of width and therefore using less width classes could be acceptable.

Based on the data from the width-distribution histograms it was possible to determine what widths to re-rip the material into uniform shorts to maximize recovery. Selecting width-classes just below (under) peaks in the histograms will minimize waste when re-ripping material into uniform widths. For example, from the yellow-poplar width histogram (Fig. 4.1d) it is possible to visually see where the majority of shorts are located; therefore width-classes should be placed just before 2 inches, 2.5 inches, and 3 inches to try and recover the most volume of material. For cherry however, (Fig. 4.1a) widths are wider and width-classes at 2 inches, 3 inches and 3.5 inches should be used to recover the most volume.

Also, the spacing of width classes can be manipulated to increase recovery. By spacing width-classes closer together near peaks in the histograms, more lumber can be recovered. Based on the histograms from all species, width-classes were chosen as reported in the methods section. The following widths (in inches) were chosen:

$1.5,2.0,2.5,2.75,3.0,3.25,3.5,4.0,4.5 "$ 
Notice that width-classes are spaced more closely together around 3.0 inches because this is where the majority of the data was concentrated.

Histograms were also created to represent the length distributions of the data (Figure 4.2).
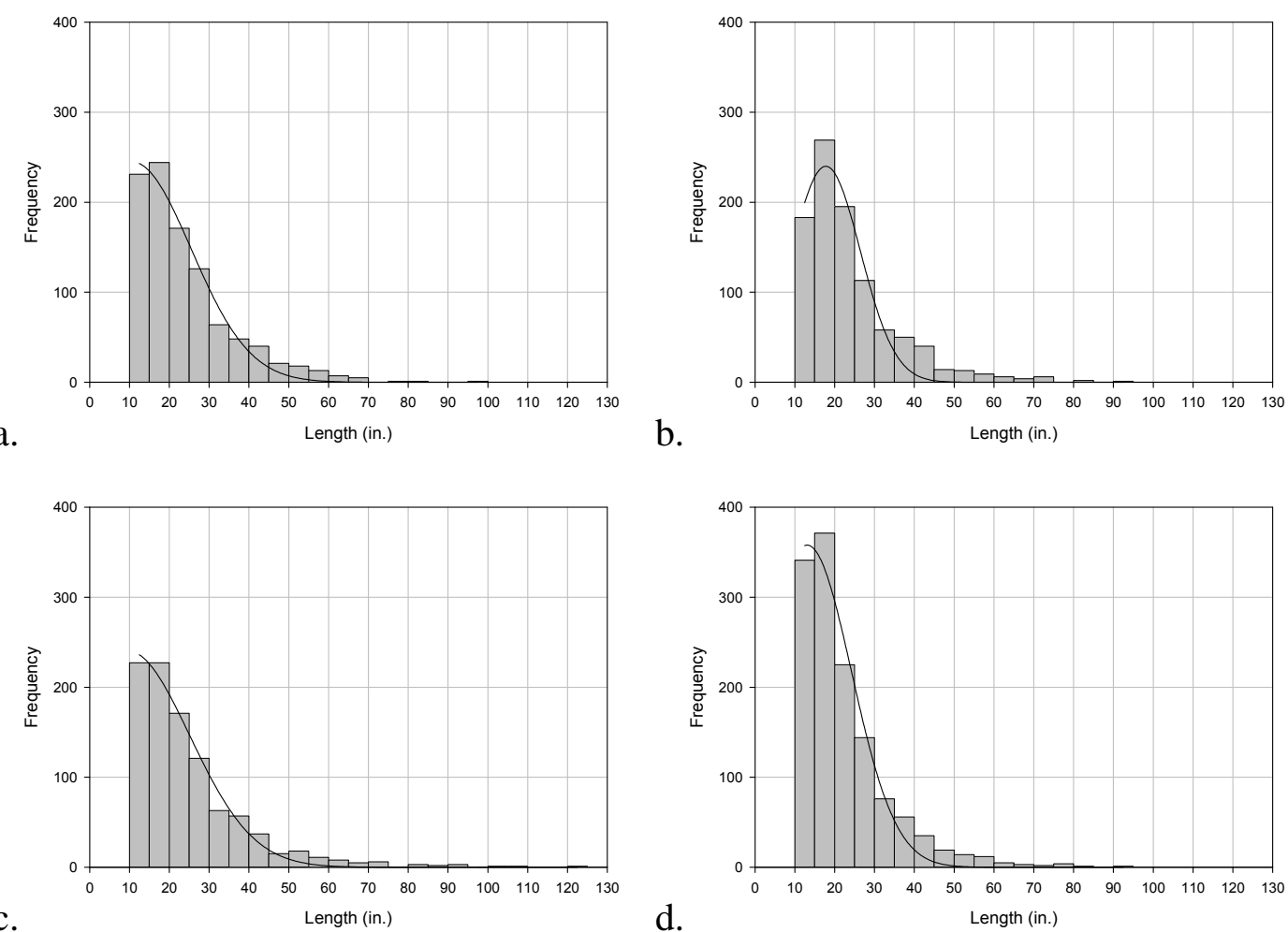

Figure 4.2 Length distributions of salvaged shorts for all phases combined for cherry (a), maple (b), red oak (c), and yellow-poplar (d).

Distributions of lengths were similar for all species. Again, all data was rightskewed because the minimum length used, mandated by finger-jointing requirements, was 12 inches. For all species, the mean length was around 22 inches however, it is visibly clear that the majority of the pieces were less than 
approximately 30 inches. This fact supports the use of finger-jointing to reconstitute low-grade lumber into longer stock because most finger-jointing machinery cannot easily handle material longer than 28 inches.

\subsection{Yields}

After measuring the random width and length shorts, the shorts were ripped into uniform-widths. Recovery of usable material was determined using different definitions of yield (\%). First, the yield of converting rough lumber into random-width and length shorts was determined. The following formula was used:

$$
\text { Yield }_{\mathrm{C}}=\frac{A_{\mathrm{C}}}{A_{\mathrm{r}}} \times 100
$$

Where:

Yield $_{\mathrm{c}}(\%)=$ Yield of clear wood from rough lumber; $A_{\mathrm{c}}=$ Area of clear shorts;

$A_{\mathrm{r}}=$ Area of rough lumber.

This yield represents the maximum amount of clear lumber salvageable from the rough lumber. Table 4.3 provides the results from these calculations for each species. 
Table 4.3 Descriptive statistics of clear lumber recovered from Phase I.

\begin{tabular}{ccccccc}
\hline \hline & \multicolumn{6}{c}{ Phase I. } \\
\cline { 2 - 7 } Species & $\mathrm{n}^{1}$ & $\begin{array}{c}\text { Yield } \\
\text { (\%) }\end{array}$ & $\begin{array}{c}\text { Mean width } \\
\text { (in.) }\end{array}$ & $\begin{array}{c}\text { Std. } \\
\text { Dev. }\end{array}$ & $\begin{array}{c}\text { Mean length } \\
\text { (in.) }\end{array}$ & $\begin{array}{c}\text { Std. } \\
\text { Dev. }\end{array}$ \\
\hline \hline Cherry & 268 & 34 & 2.66 & 1.19 & 27.32 & 16.36 \\
Maple & 400 & 36 & 2.34 & 1.07 & 22.45 & 13.51 \\
Red Oak & 354 & 48 & 3.20 & 1.98 & 23.87 & 15.51 \\
Yellow-poplar & 472 & 41 & 2.59 & 1.48 & 19.49 & 12.94 \\
\hline \hline
\end{tabular}

- $\mathrm{n}$ refers to number of shorts

2. standard deviation

For Phase I, red oak exhibited the highest yield of approximately $50 \%$. Maple had the lowest yield of $34 \%$. Phase I yields were the lowest of all three phases. This is opposite what would be expected as the lumber was salvaged green in the first phase, therefore the volume should have been higher. An approximate $6-8 \%$ volume decrease would be expected due to drying according to literature (FPL 1999). This could be partially explained by operator bias. As experience and familiarity with salvaging operations increased so did yield, as a result of being able to better identify defects and their boundaries. Due to the high amount of defects and abnormal wood surrounding the defects, it can be difficult to identify how much wood needs to be removed to eliminate the defects. Defects should be sawn through to remove them. If the defect still exists under the surface or otherwise it shoud be re-sawn again until the entire defect and surrounding abnormal wood is removed. In the first trial, too many questionable defects probably were removed (such as surface molds, discolorations, and dirt on the surface which could be misidentified as knots, decay or other defects). 
After salvaging the first phase it was easier to accomplish this task more effectively.

Also, the condition of the $3 \mathrm{AC}$ lumber could have led to lower yields. Because low-grade lumber is less valuable, often times less care is taken by sawmills when storing and transporting the lumber. Therefore low-grade lumber can often contain mechanical damage and become covered in dirt or mud which makes identifying defects more difficult. It is recommened for future yield studies and and for production settings where yield is critical that the lumber be lightly planed before salvaging to better gauge the quality of the lumber and improve accuracy of locating defects.

This however, was not plausible for our study due to the desired endproduct. The creation of finger-jointed, edge-glued panels requires lumber to be finger-jointed and then planed, edge-glued and then planed againg; therefore an additional planing at the beginning of the process would have prevented the desired thickness to be obtained.

After Phase I was completed, lumber was acquired and dired for Phase II and Phase III. Lumber was salvaged after drying to $14 \%$ MC. The shorts were measured and analyzed. Table 4.4 contains the size distributions and yields of salvaged materia for Phases II and III. 
Table 4.4 Descriptive statistics of clear material recovered from Phases II and III.

\begin{tabular}{ccccccc}
\hline \hline & \multicolumn{5}{c}{ Phases II and III. } \\
\cline { 2 - 7 } Species & $\mathrm{n}^{1}$ & $\begin{array}{c}\text { Yield } \\
(\%)\end{array}$ & $\begin{array}{c}\text { Mean width } \\
\text { (in.) }\end{array}$ & $\begin{array}{c}\text { Std. } \\
\text { Dev. }\end{array}$ & $\begin{array}{c}\text { Mean length } \\
\text { (in.) }\end{array}$ & $\begin{array}{c}\text { Std. } \\
\text { Dev. }\end{array}$ \\
\hline \hline Cherry & 758 & 45 & 2.98 & 0.96 & 21.99 & 9.31 \\
Maple & 639 & 43 & 3.12 & 1.14 & 23.45 & 10.30 \\
Red Oak & 666 & 44 & 3.10 & 1.18 & 23.38 & 12.37 \\
Yellow-poplar & 986 & 54 & 2.76 & 0.98 & 21.82 & 9.92 \\
\hline \hline
\end{tabular}

- $\mathrm{n}$ refers to number of shorts

${ }^{2}$ - standard deviation

Yields improved in Phases II and III for cherry, maple and yellow poplar as compared with Phase I, while red oak yield decreased from 48 to $44 \%$. The average yeilds of cherry, maple and red oak produced similar results of about $44 \%$. Yellow-poplar again yielded the highest volume of clear material at $54 \%$.

The average sizes of the shorts varied, however. Red oak produced the highest mean width of 3.10 inches and yellow-poplar had the lowest mean of 2.76 inches. The mean lengths of the species for Phases II and III did not vary greatly; The Coefficient of Variance was only about 4\%. Yellow-poplar produced the lowest mean lengths followed by cherry, red oak and maple.

Yellow-poplar yielded the smallest mean width and length; however, produced approximately 25 to $33 \%$ more shorts than the other three species investigated. 


\subsection{Uniform-Width Lumber}

After random-sized shorts were measured and analyzed, they were reripped to create uniform-width shorts compatible with finger-jointing operations. Nine width-classes were used to re-salvage the material in an attempt to maximize recovery as described in section 3.2.2. Shorts were then re-measured and provided the data needed to compute the yields of transforming rough lumber into uniform-width material. Equation 7 was used to determine this yield.

$$
\text { Yield }_{\mathrm{u}}=\frac{A_{\mathrm{u}}}{A_{\mathrm{r}}} \times 100
$$

Where:

Yield $_{\mathrm{u}}(\%)=$ Yield of uniform material from rough lumber;

$A_{\mathrm{u}}=$ Area of uniform shorts;

$A_{\mathrm{r}}=$ Area of rough lumber.

The following table describes the results from re-salvaging the randomwidth material into uniform widths for all phases combined. 
Table 4.5 Yield of uniform-width shorts recovered from 1,200 BF, 4/4 thickness rough lumber per species.

\begin{tabular}{cccc}
\hline \hline & \multicolumn{3}{c}{ Uniform-Width Shorts } \\
\cline { 2 - 4 } Species & $\mathrm{n}^{1}$ & Yield (\%) & Volume (BF) \\
\hline \hline Cherry & 969 & 37.5 & 449.6 \\
Maple & 947 & 36.2 & 434.0 \\
Red Oak & 999 & 42.1 & 505.5 \\
Yellow-poplar & 1,335 & 44.7 & 536.9 \\
\hline \hline
\end{tabular}

1- number of shorts

The reduction in yields from random-width to uniform widths was calculated for each species. The average yield loss was $4.1 \%$ for the four species. Re-ripping cherry and red oak resulted in the least loss of material at approximately $3.5 \%$. This similarity in reduction coincides with the fact that both species were distributed similarly as represented by width histograms. Reripping yellow-poplar resulted in the greatest loss at $5.0 \%$ followed by maple at $4.1 \%$.

This may be explained by the high amount of narrow shorts less than 1.5 inches that were not able to be included in the uniform-width data for yellowpoplar. Uniform-width shorts were wrapped in plastic to prevent moisture content changes and stored until they were finger-jointed. 


\subsection{Finished Panel Yield Determination}

After shorts were prepared into uniform widths, a portion of the specimens were finger-jointed, moulded, and edge-glued into panels as described in Section 3.3. Based on the recovery results from these processes, a deterministic model was created to predict the yields of converting rough lumber into finished panels.

Random-width and length data from each phase was combined into one file for each species. These databases contained approximately 1,000-1,500 shorts per species.

This data was first manipulated to represent the conversion of randomwidth shorts into uniform-width shorts. These calculations were done by filtering the data into width-classes. The actual lumber was re-ripped into nine different width-classes: 1.5”, 2.0", 2.5”, 2.75", 3.0", 3.25", 3.5", 4.0", and 4.5". By filtering the data into these width-classes, the dimensions and volumes of uniform-width shorts was determined.

Once uniform-width yields were determined for each species using ninewidth-classes, the data was filtered again using a fewer number of width-classes. Table 4.6 shows the number of width-classes and different widths used for this analysis. 
Table 4.6 Number of width-classes and widths used to re-rip material.

No. of Width-classes

9

7

5

3
Widths Used

1.5", 2.0", 2.5", 2.75", 3.0", 3.25", 3.5", 4.0", and 4.5"

1.5", 2.0", 2.5", 3.0", 3.5", 4.0", and 4.5"

2.0", 2.5", 3.0", 3.5", and 4.0"

2.0", 3.0", and 4.0"

Yield differences were then compared to provide information about the benefits of utilizing different numbers of width-classes. After uniform-width data was determined, additional volume losses were accounted for. All pieces of lumber longer than 28 " needed to be filtered to represent cross-cutting operations. This resulted in the creation of two or more shorts and a loss of 0.25 " in length due to saw kerf per cross-cut

Lumber wider than the highest width-class was analyzed and determined how to best re-rip to achieve the greatest yield (example: a 6" wide short could be ripped into one 2.75 " wide short and one 3.0 " short, thus total width loss would equal 0.25 "; as opposed to ripping the 6 " width into the 4.5 " width-class and creating 1.5" width loss).

Performing these calculations provided the total volume of uniform-width, ready-to-finger-joint material. Length and width reductions were then determined for losses due to finger-jointing and moulding operations. 
The finger-jointing operations reduced only the length of the shorts. The length reductions were determined from the actual data collected from fingerjointed specimens. A general formula was used to calculate length losses:

$$
L=n \times\left(T_{r}+L_{f}\right)
$$

Where:

$L=$ Length loss (in.)

$n=$ number of shorts

$T_{r}=$ Trim cut loss (in.) (0.125")

$L_{f}=$ Length of finger (in.) (0.405)

Both horizontal and vertical finger-joint cutter-heads used the same length of finger; therefore few changes were necessary when simulating length losses for either of the two types of joints. Vertical finger-jointing operations utilized a trim saw that squared shorts just before they were jointed. Horizontal finger-jointing did not use a trim saw, however the cutter-head was set-up to remove slightly more than the length of the fingers, essentially performing the same objective as the trim saw. This data provided the information needed to calculate the lengths of material after finger-jointing. Dimension losses associated with surfacing operations were then calculated.

Width losses occurred when blanks were moulded in preparation for edgegluing. From the actual process of surfacing blanks it was established that the 
blanks would lose 0.25 " total in width $(0.125$ " on each edge). With the total volume of finger-jointed, moulded lumber established, the volume of panels producible was determined.

The lengths of surfaced blanks were divided by the length of finished panels to determine the number of staves producible. This was done by dividing the total length of a blank by the desired length of the panel plus losses in saw kerf resulting from cross-cutting.

Example: If there were 300 linear $\mathrm{ft}$ of $3.0 \mathrm{in}$. width material, the length was divided by 38.25 " (panel length + saw kerf) to obtain the number of staves producible:

Number of staves $=300$ linear $\mathrm{ft} \times 12$ in. $=3,600$ linear in. $/ 38.25$ in. $=$ 94.1

Thus, 94.1 staves may be produced from that width-class. The 0.1 stave leftover should not be considered waste. The area of the leftover stave may be calculated by multiplying $0.1 \times 38.25$ in. $=3.825 \times 3.0$ in. width $=$ $11.5 \mathrm{in}^{2}$.

This area should not be considered waste because in industrial operations the finger-joint operator has the capability of creating continuous lengths of material and would be able to utilize that extra length (Figure 4.3). 


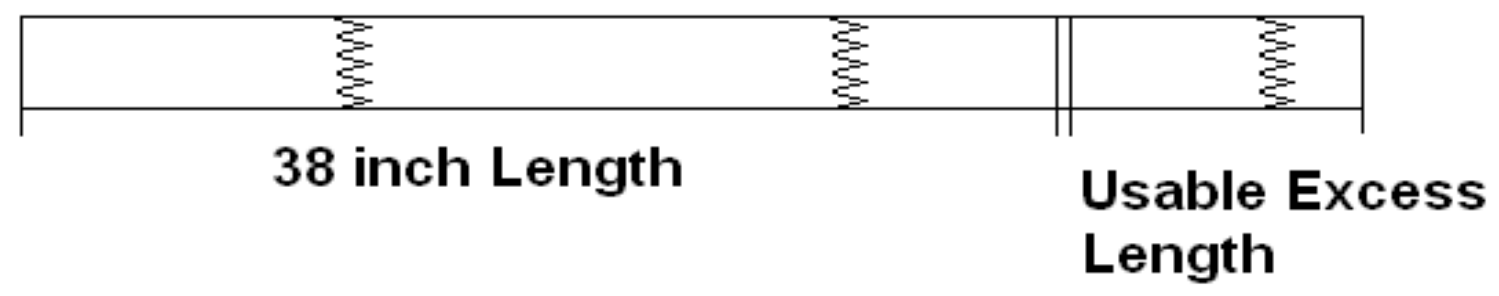

Figure 4.3 Example of usable excess length of material.

After the number of staves available was determined, steps were taken to calculate finished panel area. The panels were created by edge-gluing the staves to reach the appropriate width. Therefore, the number of staves required to create a panel depends on the width of the stave. To determine the number of staves needed to create a finished panel, the width of the panel (26") was divided by the width of the stave:

Example: Number of staves needed $=26$ in. width $/ 3.0$ in. width-class $=$ 8.66.

So, a total of 9 staves are required to create one panel. The amount of waste associated with excess width of staves can be calculated by multiplying $0.33 \times 3.0 \mathrm{in}$. width $\times 38 \mathrm{in}$. length $=37.6 \mathrm{in}^{2}$. This area represents what excess will be trimmed off the edge of each panel produced at that width-class.

Considerations should be taken to minimize this waste (Figure 4.4). 


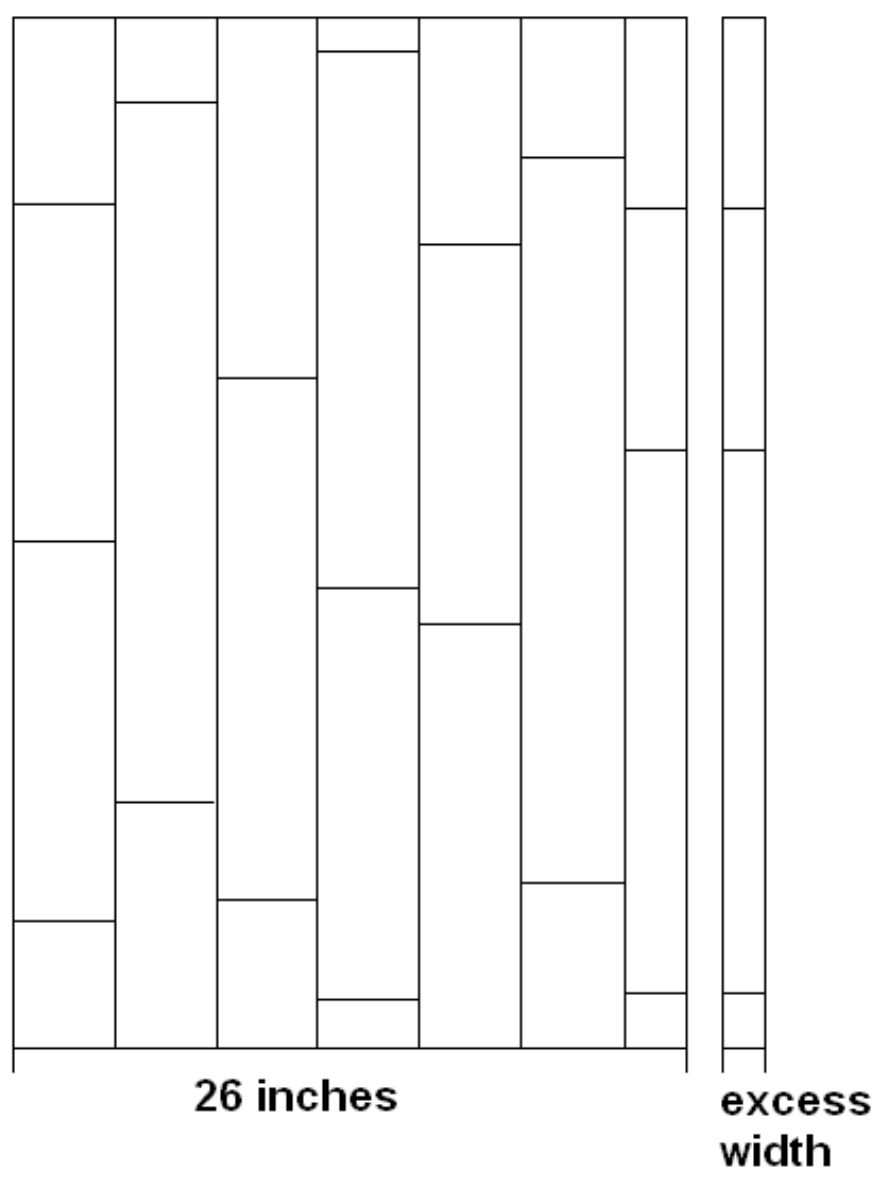

Figure 4.4 Example of excess wood after trimming to 26 in. width.

Some width-classes of staves produced less waste than others. Table 4.7 reports width-classes and corresponding waste associated with the trimming process. 
Table 4.7 Excess wood material created by forming 26 in. wide panels.

\begin{tabular}{ccccc}
\hline $\begin{array}{c}\text { Width-Class } \\
\text { (in.) }\end{array}$ & $\begin{array}{c}\text { Dressed Width } \\
\text { (in.) }\end{array}$ & $\begin{array}{c}\text { No. Staves } \\
\text { Needed }\end{array}$ & $\begin{array}{c}\text { Excess Width } \\
\text { (in.) }\end{array}$ & $\begin{array}{c}\text { Area of Solid Wood } \\
\text { Excess (sq. }{ }^{2} \text { ) }\end{array}$ \\
\hline \hline 1.50 & 1.25 & 21 & 0.00 & 0.00 \\
2.00 & 1.75 & 15 & 0.00 & 0.00 \\
2.50 & 2.25 & 12 & 0.74 & 28.12 \\
2.75 & 2.50 & 11 & 1.25 & 47.50 \\
3.00 & 2.75 & 10 & 1.26 & 47.98 \\
3.25 & 3.00 & 9 & 0.74 & 28.12 \\
3.50 & 3.25 & 8 & 0.00 & 0.00 \\
4.00 & 3.75 & 7 & 0.01 & 0.48 \\
4.50 & 4.25 & 7 & 3.49 & 132.62 \\
\hline \hline
\end{tabular}

From Table 4.7, it is possible to see width-classes $1.50,1.75$, and 3.50 all result in less than $0.25 \mathrm{in}$. leftover in width, resulting in no solid wood material after trimming with a saw kerf of 0.25 in. On the contrary, width-class 4.50 results in a 3.49 in. wide strip of solid wood left over. This material could be salvaged and reused assuming the trimming process created an edge ready for gluing. Width-classes $2.50,3.25$, and 4.00 all resulted in solid wood strips that were less than $0.75 \mathrm{in}$. wide and are too narrow to be re-used. Therefore, based solely on yields, these width-classes should be avoided for the production of 26 in. wide panels. The width of the staves and width of the panels should be coordinated to minimize waste either by changing the width of the finished panel or altering the width of the staves.

Table 4.7 also provides the information necessary to determine the number of glue lines needed per panel by width-class. The number of glue lines 
is equal to one minus the number of staves needed. This will affect the cost of glue as well as panel lay-up time and energy. Width-class 1.50 requires 20 gluelines $\left(\sim 1.0\right.$ " thickness $\times 38$ " length $\times 20$ glue lines $\left.=760 \mathrm{in}^{2}\right)$, whereas width-class 4.5 will require only 6 glue lines $\left(228 \mathrm{in}^{2}\right)$, about $1 / 3$ the amount of glue. The cost of glue is low relative to the overall cost of the operation, however the extra time involved in applying and handling the pieces will reduce productivity as well as increase raw material costs.

Finally, the total number of panels producible was determined by dividing the number of staves available by the number of staves needed to produce one panel:

Example: We had 94, 3.0 in. width staves. By dividing 94 (no. of staves) by 9 (no. of staves needed for one panel $)=10.4$ So, ten panels could be created from this width class. Now this data can be added to the other width classes for that species to determine the total finished area of the species.

The area of finished panels was used to determine the overall yield from rough lumber to finished product. Equation 8 was used to calculate this yield. 


$$
\text { Yield }_{\mathrm{f}}=\frac{A_{\mathrm{f}}}{A_{\mathrm{r}}} \times 100
$$

Where:

Yield $_{\mathrm{f}}(\%)=$ Yield of finished panels from rough lumber;

$A_{\mathrm{f}}=$ Area of finished panels;

$A_{\mathrm{r}}=$ Area of rough lumber.

From these data transformations the total finished area for each species was predicted. The results from these procedures may be seen in Figure 4.5 represented as yield (\%) from rough lumber to finished panel.

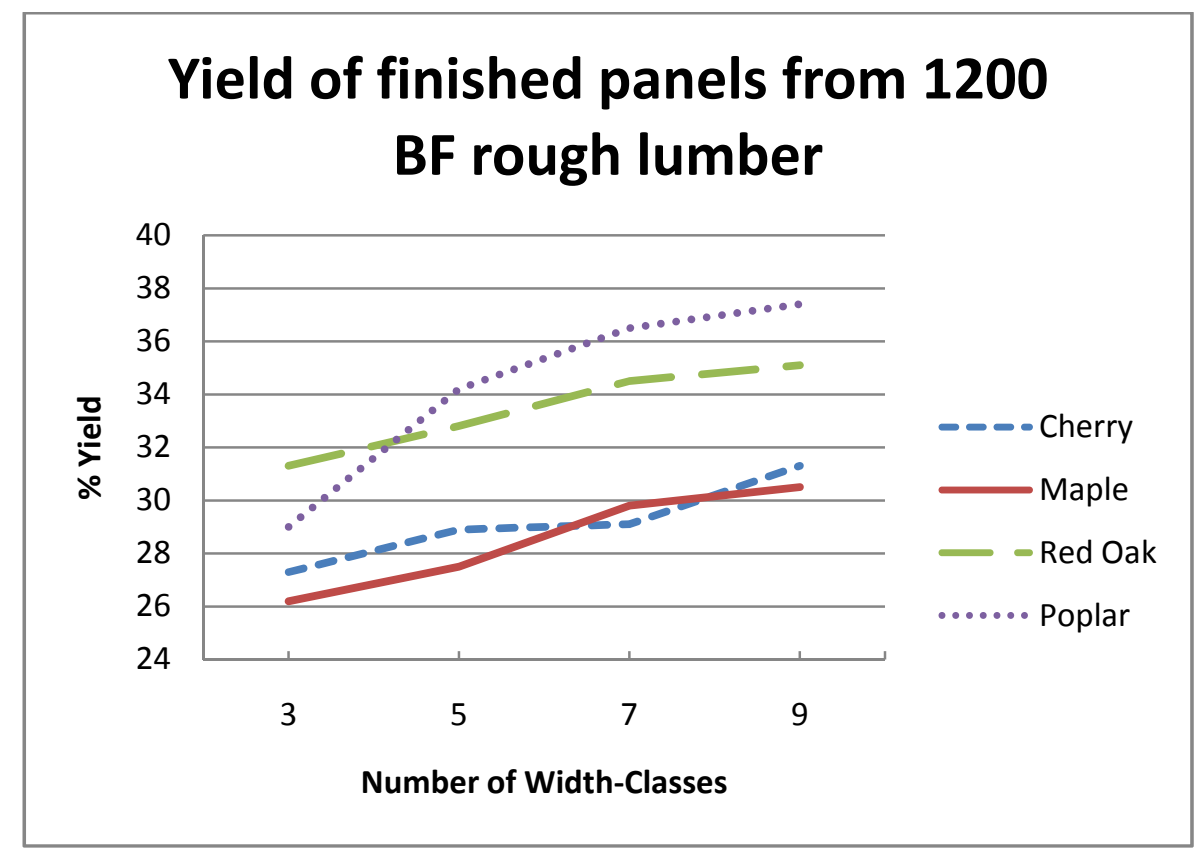

Figure 4.5 Yield of finished panels produced from rough lumber by species and number of width-classes used. 
Yellow-poplar yielded the highest area followed by red oak, cherry and maple. Cherry and maple both produced similar yields. Based on Figure 4.4 it is possible to assess the impact number of width-classes has on yields.

Each species reacted slightly differently from width-class to width-class. All species experienced increases in yield when moving from 3-width-classes to five width-classes. Yellow-poplar increased the greatest percentage during this period. Cherry, maple and red oak all increased similarly. Switching from 5width-classes to 7-width-classes, maple, red oak, and yellow-poplar experienced similar increases, however cherry saw little improvement in yield. In this case it would not make sense to salvage the cherry with 7-width-classes. Maple had little increase in yield when moving from 7-width-classes to 9-width-classes. Cherry, red oak and yellow-poplar all increased similarly in this class group.

This predicted yield data can be used to compare yield increases with the corresponding cost increases associated with utilizing greater numbers of widthclasses. Utilizing more width-classes will result in additional material handling and storage costs. This is discussed in the following section.

\subsection{Costs-Benefit Analysis}

The economic profitability of the production processes was estimated using a simple cost-benefit analysis. To accomplish this, the costs of producing finger-jointed, edge-glued hardwood panels were compared to the current 
estimated value of the finger-jointed, edge-glued panels. Total costs included simply operational costs and raw material costs.

\subsubsection{Costs}

\subsubsection{Raw Material Costs}

Current market prices for $4 / 4$ thickness, No. 3A Common lumber were obtained from the September 6, 2008 issue of the Hardwood Market Report. Because the Hardwood Market Report does not give values for all kiln-dried No. 3A Common species of lumber, kiln drying costs were estimated and added to the cost (Table 4.8).

Table 4.8 Costs of No. 3A Common lumber per 1000 BF.

\begin{tabular}{cccc}
\hline \hline Species & No. 3A Common & $\begin{array}{c}\text { Kiln-Drying } \\
\text { Costs }\end{array}$ & Total Lumber Costs \\
\hline \hline Cherry & $\$ 380$ & $\$ 100$ & $\$ 480$ \\
Soft Maple & $\$ 220$ & $\$ 100$ & $\$ 320$ \\
Red Oak & $\$ 415$ & $\$ 100$ & $\$ 515$ \\
Yellow-Poplar & $\$ 240$ & $\$ 100$ & $\$ 340$ \\
\hline \hline
\end{tabular}


Glue costs were then added to the raw material cost. Costs of glue for edgeglued panel manufacturing were based on a previous study by Weidenbeck (1994). The glue cost was increased for inflation and added to the raw material cost and operating costs to calculate total costs of processing $1000 \mathrm{BF}$ of rough lumber. Glue costs for finger-jointing were included in the operating costs.

\subsubsection{Operating Costs}

Operating costs were estimated using a combination of operating costs cited in Araman and Hansen (1983) and Weidenbeck (1994). An operating cost per $1000 \mathrm{BF}$ was established from these two studies and adjusted for inflation. These estimates reflected operating costs at a rough mill manufacturing dimension lumber and creating edge-glued (non- finger-jointed) panels. Costs also were adjusted to account for the use of low-grade lumber for this project. Steel et al., (1999) investigated the effect lumber grade had on productivity in a rough mill. The results indicated that changes in lumber grade significantly affect productivity. Therefore the costs cited in the two studies were increased to estimate the increased costs of processing low-grade lumber.

The addition of finger-jointing operations was roughly estimated to increase costs by a maximum of $25 \%$ of the total operational costs. This is based on the costs to produce solid wood panel manufacturing costs derived from the previously stated literature and the addition of process related to finger- 
jointing operations. The previously stated literature included operational costs for salvaging rough lumber by ripping into uniform widths and then cross-cutting into a range of lengths desirable for edge-glued panels. The strips of lumber were then sorted and edge-glued to create panels, trimmed and planed to final dimensions. For the proposed process of finger-jointing certain additional steps need to be added.

First, strips are cross-cut at random lengths and then finger-jointed to create long stock. Finger-jointed material must then be moulded on four sides in order to be properly edge-glued. After edge-gluing, the material is just the same as in the previous studies. The utilization of many width-classes requires an increase in operation costs because storage and handling issues will become more complicated. The actual magnitude of this increase on operating costs is unknown. Therefore, the volume of material that would be recovered using 5width-classes was used for the benefit section. This is due to the fact that operation costs cited in the Wiedenbeck (1994) study were based on a process that utilized many different widths and the utilization of 5-width-classes should not greatly affect the process.

Based on this information, an operational cost per 1,000 BF was estimated. The total operating cost, including finger-jointing costs and inflation, was estimated at $\$ 1,130$ per $1000 \mathrm{BF}$. 


\subsubsection{Total Costs}

Total costs were calculated for each species assuming by adding operational costs to lumber costs. The total cost per species is located in Table 4.9.

Table 4.9 Total costs to process 1,000 BF rough lumber into finished panels.

\begin{tabular}{ll}
\hline \hline \multicolumn{1}{c}{ Species } & Total Cost \\
\hline \hline Cherry & $\$ 1,796.43$ \\
Maple & $\$ 1,670.35$ \\
Red Oak & $\$ 1,840.59$ \\
Yellow-poplar & $\$ 1,626.51$ \\
\hline \hline
\end{tabular}

\subsubsection{Benefits}

The value of the finished panels was calculated for each species and for a number of width-classes based on the yield determinations described in section 4.3. Value was determined by multiplying the area of finished panels by the current price of edge-glued panels.

Prices were obtained from a sample of hardwood edge-glued panels available in the U.S. and abroad. Also, prices are included from previous studies however; these values were much lower than those currently found on the market. The price/ft $\mathrm{ft}^{2}$ of common edge-glued panels of each species is located in 
Table 4.10 with the highlighted areas representing estimated prices for the respective species.

Table 4.10 Value of finished panels produced from 1,000 BF rough lumber per species.

\begin{tabular}{ccccccc}
\hline \hline & & \multicolumn{5}{c}{ (\$) Price per $\mathrm{ft}^{2}$} \\
\cline { 3 - 7 } Species & Area (ft $\left.{ }^{2}\right)$ & $\$ 10.00$ & $\$ 8.00$ & $\$ 6.00$ & $\$ 4.00$ & $\$ 3.00$ \\
\hline \hline cherry & 376 & $\$ 3,758$ & N/A & N/A & N/A & N/A \\
maple & 365 & N/A & N/A & $\$ 2,193$ & N/A & N/A \\
red oak & 422 & N/A & $\$ 3,373$ & N/A & N/A & N/A \\
yellow-poplar & 448 & N/A & N/A & N/A & N/A & $\$ 1,345$ \\
\hline \hline
\end{tabular}

The area of finished panels produced by salvaging 1,000 BF rough lumber for each species, at each set of width-classes, was multiplied by the price/ft² to determine the value. As the number of width-classes increased, so did the yield and corresponding value. Table 4.11 represents the value of processing 1000 BF rough lumber for each species, utilizing four sets of width-classes. 
Table 4.11 Value of finished panel area per 1,000 BF by species and number of width-classes.

\begin{tabular}{ccccc}
\hline & \multicolumn{4}{c}{ Number of Width-classes } \\
\cline { 2 - 5 } Species & 3 & 5 & 7 & 9 \\
\hline \hline Cherry $^{1}$ & $\$ 3,279$ & $\$ 3,474$ & $\$ 3,496$ & $\$ 3,758$ \\
Maple $^{2}$ & $\$ 1,884$ & $\$ 1,982$ & $\$ 2,143$ & $\$ 2,193$ \\
Red Oak $^{3}$ & $\$ 3,006$ & $\$ 3,146$ & $\$ 3,314$ & $\$ 3,373$ \\
Yellow-poplar & $\$ 1,142$ & $\$ 1,232$ & $\$ 1,314$ & $\$ 1,345$ \\
\hline \hline
\end{tabular}

1- Value based on $\$ 10.00 / \mathrm{ft}^{2}$

2- Value based on $\$ 6.00 / \mathrm{ft}^{2}$

3 -Value based on $\$ 8.00 / \mathrm{ft}^{2}$

4 -Value based on $\$ 3.00 / \mathrm{ft}^{2}$

Based on these values, profit was estimated. It should be noted that due to the variability of the values the results should be interpreted cautiously.

\subsubsection{Profit}

Profits were estimated by subtracting the total costs by the value of finished panels. The results of profit may be seen in Table 4.12. 
Table 4.12 Profit from processing 1,000 BF of rough lumber based on recovered yields by species and number of width-classes used.

\begin{tabular}{ccccc}
\hline & \multicolumn{4}{c}{ Number of Width-classes } \\
\cline { 2 - 5 } Species & 3 & 5 & 7 & 9 \\
\hline \hline Cherry & $\$ 273$ & $\$ 468$ & $\$ 490$ & $\$ 752$ \\
Maple & $\$ 148$ & $\$ 246$ & $\$ 407$ & $\$ 457$ \\
Red Oak & $\$ 251$ & $\$ 391$ & $\$ 559$ & $\$ 618$ \\
Yellow-poplar & $\$ 32$ & $\$ 122$ & $\$ 204$ & $\$ 235$ \\
\hline \hline
\end{tabular}

Profits were highest for cherry and red oak and lowest for yellow-poplar. As noted in the costs section, additional costs associated with utilizing more width-classes were not factored into the calculations.

\subsection{Mechanical Properties}

Static bending tests were performed to evaluate the mechanical properties of the finger-jointed panels. Modulus of elasticity (MOE) and modulus of rupture (MOR) were determined by testing specimens to failure in bending. Table 4.13 contains the summary results of MOE of the test specimens. 
Table 4.13 Stiffness (MOE x $10^{6} \mathrm{psi}$ ) results of finger-jointed and control specimens.

\begin{tabular}{cccccc}
\hline \hline Sample Codes & $\mathrm{n}^{1}$ & Mean $\left(\mathrm{psi} \times \mathrm{N0}^{6}\right)$ & $\begin{array}{c}\text { Std. } \\
\text { Dev. }^{2}\end{array}$ & Min. (psi x106) & Max. (psi x106) \\
\hline \hline Cherry Horizontal Joint & 10 & 1.34 & 0.10 & 1.18 & 1.46 \\
Cherry Vertical Joint & 10 & 1.47 & 0.19 & 1.29 & 1.96 \\
Cherry Solid & 10 & 1.58 & 0.17 & 1.43 & 1.74 \\
\hline Maple Horizontal Joint & 10 & 1.35 & 0.14 & 1.14 & 1.59 \\
Maple Vertical Joint & 10 & 1.37 & 0.21 & 1.06 & 1.73 \\
Maple Solid & 10 & 1.62 & 0.25 & 1.22 & 1.91 \\
\hline Oak Horizontal Joint & 10 & 1.62 & 0.18 & 1.25 & 1.84 \\
Oak Vertical Joint & 10 & 1.68 & 0.20 & 1.37 & 2.02 \\
Oak Solid & 10 & 1.98 & 0.35 & 1.34 & 2.60 \\
\hline \hline
\end{tabular}

1 - sample size

2. standard deviation

Horizontally finger-jointed lumber exhibited the lowest MOE of all specimens tested. Solid wood specimens demonstrated the highest MOE values as was expected. MOE values were compared using One-way ANOVA as described in the statistical methods section. The results of these comparisons are located in Appendix III. Figure 4.6 shows some examples of failure for the two different finger-joint orientations. 

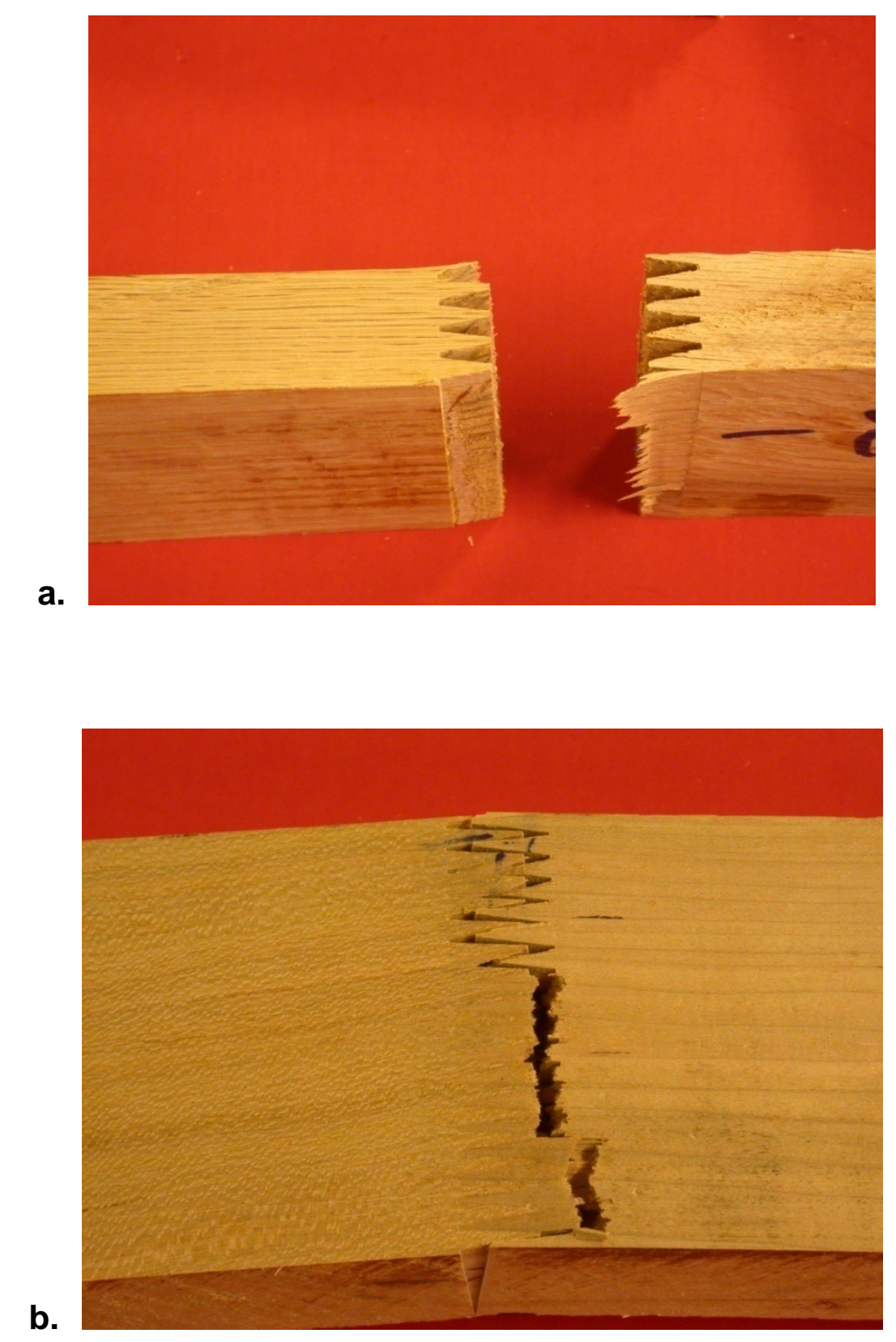

Figure 4.6 Typical failure in bending; horizontally finger-jointed lumber (a), and vertically jointed lumber (b).

Table 4.14 provides the results of MOR determination. All finger-jointed specimens exhibited significantly lower MOR values compared to solid wood. 
Table 4.14 Bending strength (MOR, psi) results of finger-jointed and control specimens.

\begin{tabular}{cccccc}
\hline \hline Sample Codes & $\mathrm{n}^{1}$ & $\begin{array}{c}\text { Mean } \\
(\mathrm{psi})\end{array}$ & $\begin{array}{c}\text { Std. } \\
\text { Dev. }^{2}\end{array}$ & $\begin{array}{c}\text { Min. } \\
(\mathrm{psi})\end{array}$ & $\begin{array}{c}\text { Max. } \\
(\mathrm{psi})\end{array}$ \\
\hline \hline Cherry Horizontal Joint & 10 & 7467 & 1554 & 5199 & 10664 \\
Cherry Vertical Joint & 10 & 10472 & 1318 & 9066 & 13034 \\
Cherry Solid & 10 & 13008 & 2821 & 11256 & 16263 \\
\hline Maple Horizontal Joint & 10 & 8623 & 1201 & 5791 & 10129 \\
Maple Vertical Joint & 10 & 10496 & 1950 & 6677 & 13069 \\
Maple Solid & 10 & 14869 & 3262 & 10173 & 18471 \\
\hline Oak Horizontal Joint & 10 & 8511 & 1687 & 6697 & 11944 \\
Oak Vertical Joint & 10 & 8931 & 2055 & 6099 & 12984 \\
Oak Solid & 10 & 19261 & 3163 & 13652 & 26389 \\
\hline \hline
\end{tabular}

\footnotetext{
1. sample size

2. standard deviation
}

Horizontally finger-jointed specimens had the lowest mean values of all specimens tested. This could be partially due to the reduced surface area of horizontal fingers compared to vertical fingers.

MOR of vertically finger-jointed boards was statistically higher than horizontally jointed lumber for cherry and maple species. There were no significant differences among oak finger-jointed specimens. MOR of solid wood was significantly higher than both forms of finger-jointed specimens. Horizontally finger-jointed lumber performed worse than vertically oriented joints.

This could be caused by two different factors. First, vertically oriented finger-joints were produced using the machinery available at Weinig Inc. by experienced personnel. This properly set-up, automated machine should have produced more reliable and consistent jointing quality compared to the manually operated set-up used to produce horizontal finger-joints. Also, the geometry for 
the cutter-heads differed in some aspects that could affect mechanical properties.

Vertical finger-joints provided greater surface area for bonding than the horizontally oriented finger-jointed lumber. Surface areas were computed for both types of finger-joint configurations for 2.75 inch wide test specimens. Horizontal-joints provided approximately $4.2 \mathrm{~cm}^{2}$ of surface area to be bonded, while vertical-joints provided more than double the surface area of approximately $9.8 \mathrm{~cm}^{2}$. Figures 4.7 and 4.8 show typical failure horizontally and vertically jointed lumber.

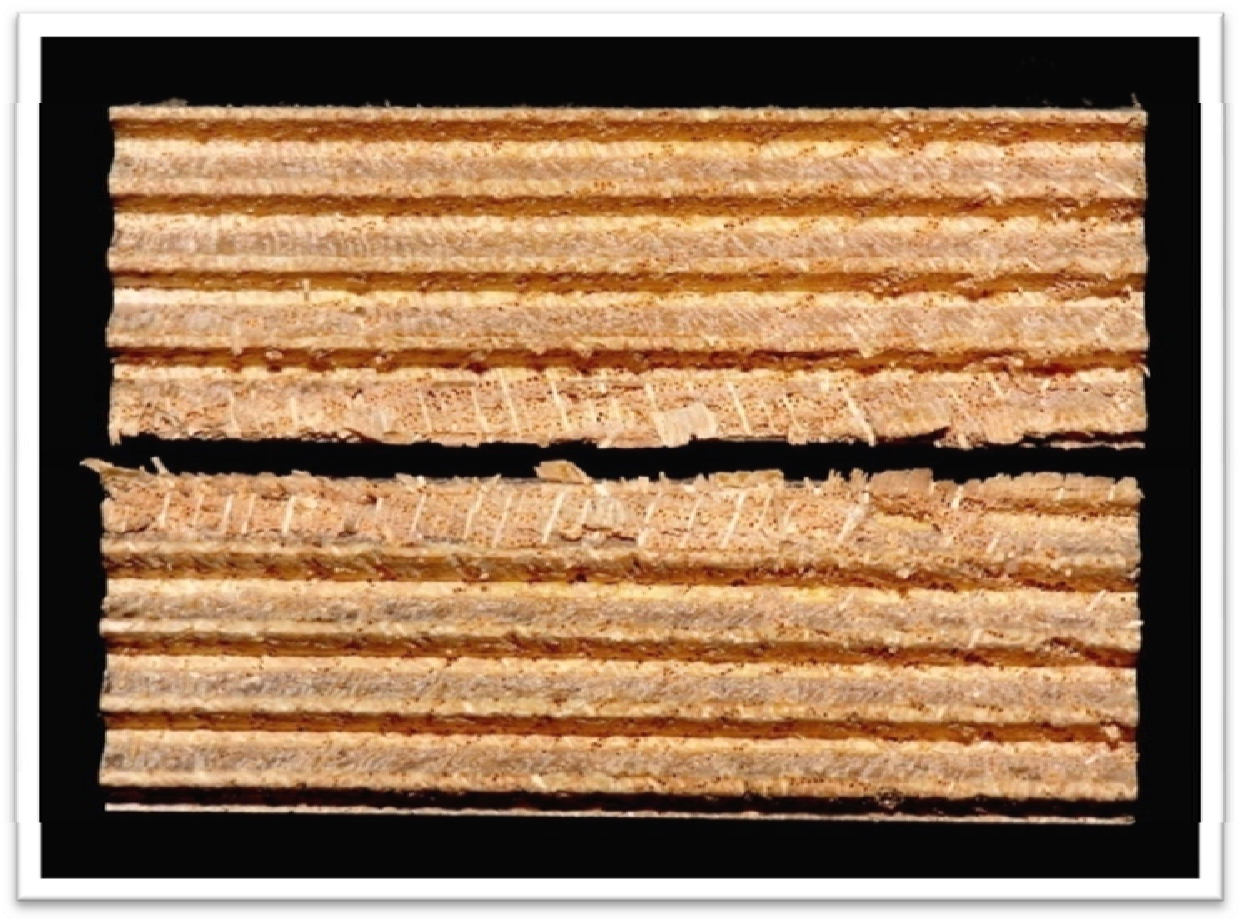

Figure 4.7 20\% wood-failure of horizontally finger-jointed red oak test specimen. 


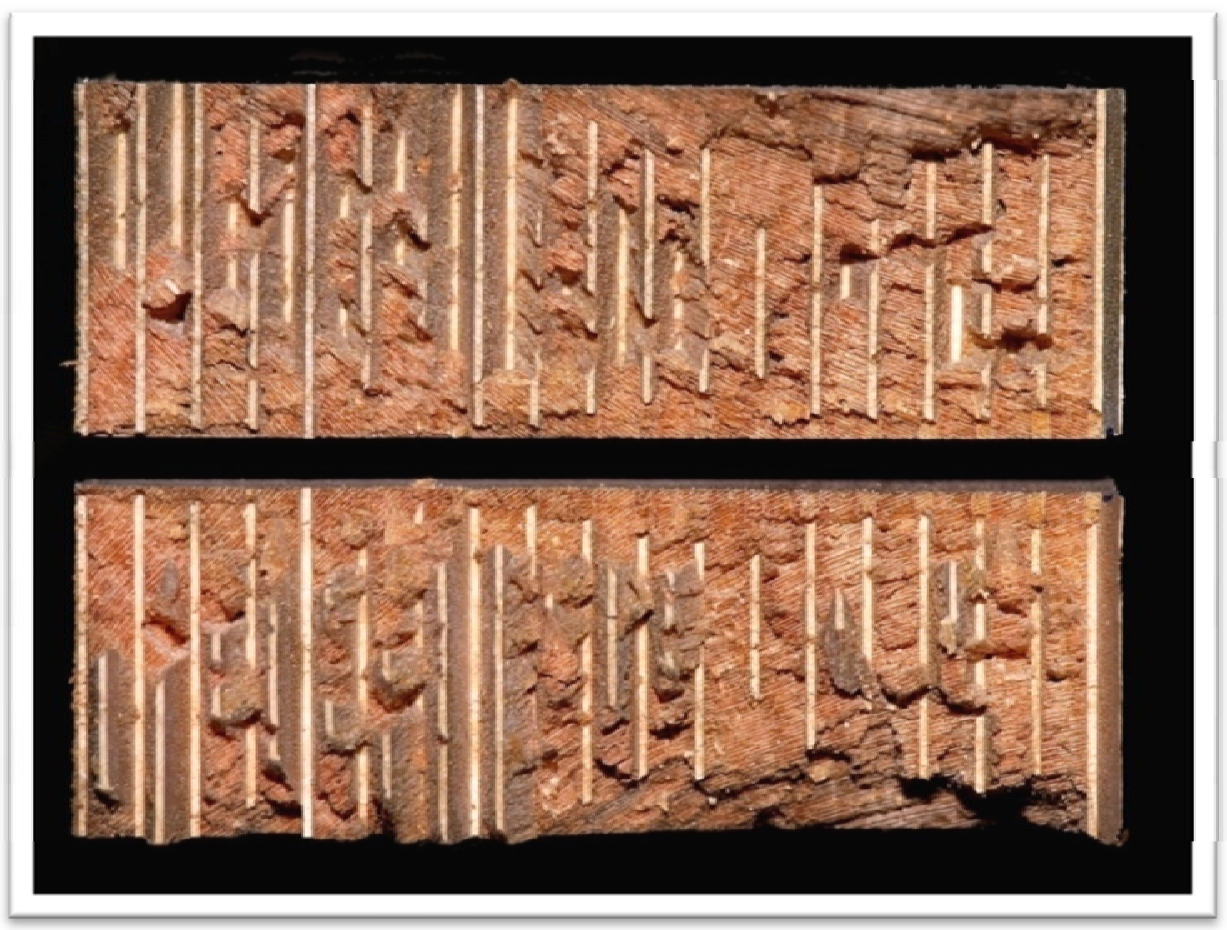

Figure 4.8 90\% wood-failure of vertically finger-jointed cherry test specimen.

In figure 4.7, a horizontally finger-jointed oak specimen has mostly failed in the glue-line, which was common for oak species. Figure 4.8 shows a cherry specimen with a high percentage of wood failure.

\subsection{Dimensional stability}

Warp measurement information collected was analyzed and compared to determine if one species or joint configuration performed better when subjected to environmental changes. A relationship was attempted to be established between the width of the staves that made up the panel and the amount of cup 
witnessed. The hypothesis was that the narrower the staves, the less amount of warping would occur. However, no significant differences could be established due to the high variation of warp and small sample size.

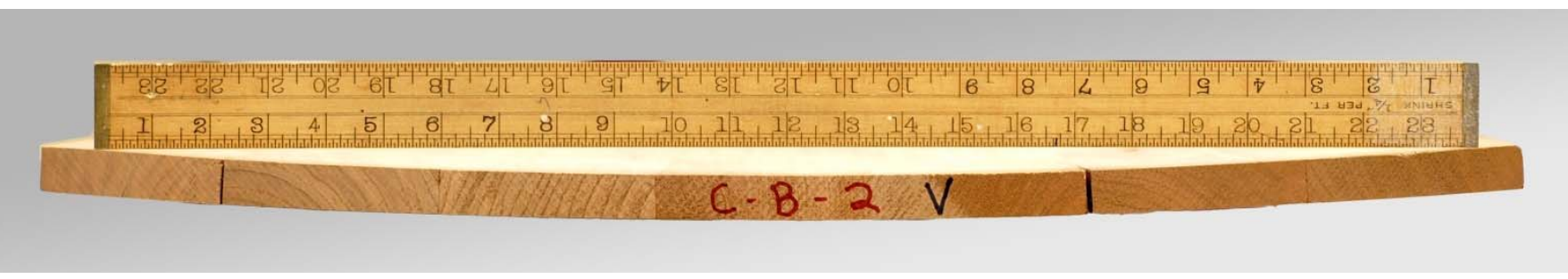

Figure 4.10 Example of severe cup in cherry, edge-glued panel.

Because the length of the panels was 38 inches, a minimum of 2 and maximum of 3 individual shorts made up each stave. For a 1.50 inch widthclass, 21 staves were needed to equal the 26 inch width; therefore a total of 63 individual shorts could go into creating one standard-size panel. As a result of this, it is not feasible to orient the ring direction of the staves to control warp as may be done in solid wood panel manufacturing. Ring orientation can be controlled prior to finger-jointing process however, and there are many benefits to doing so. The downfall is the increased sorting, handling and storing requirements associated with this. This is discussed further in the following section.

Also visible in Figure 4.10, are splits occurring along the glue lines at the end of panels. Splits along glue lines occurred among many of the panels after subjected to environmental changes. This was a result more of machining error and had no relation to ring orientation or stave width. 


\subsection{Machining and Edge-glued Panel Manufacturing Concerns}

Splits occurred along the glue line of approximately $30 \%$ of panels largely due to machining error during the moulding process (Figure 4.11).

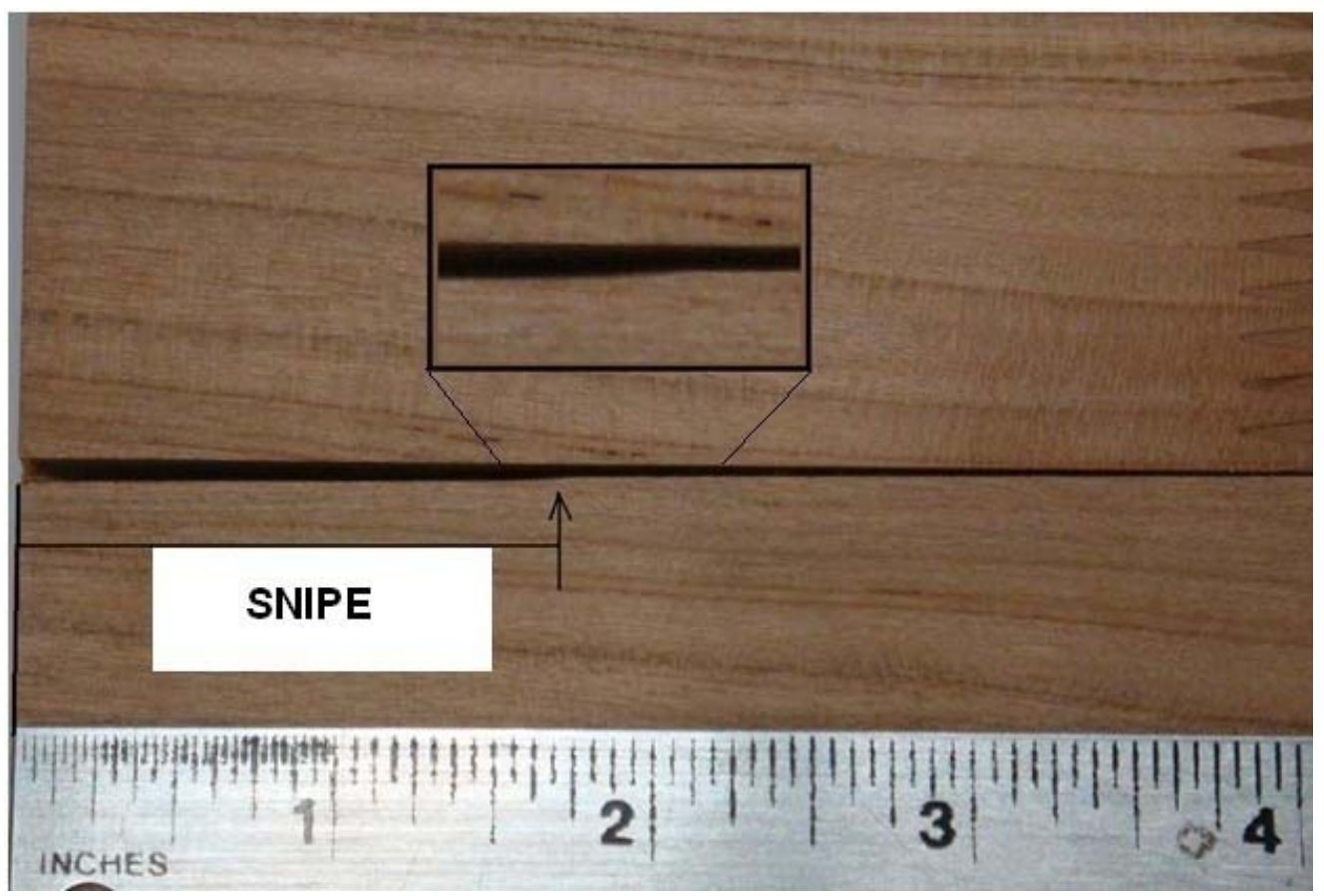

Figure 4.11 Example of end split in finished cherry panel caused by snipe.

The difference in thickness highlighted in the above figure is referred to as snipe. Snipe occurs as a result of improperly maintained or adjusted machinery. This can result in non-parallel edges resulting in uneven glue spread and pressure (Forbes et al. 1997). This difference may not be visible to the eye and therefore is very difficult to detect. Machinery must be accurately calibrated to prevent this and must be precisely checked with calipers to ensure no differences exist. The inclusion of sniped lumber in the production of edge-glued panels will result in major quality control concerns. 
For this project sniped ends could have been removed when detected by cross-cutting to remove the defected ends of blanks however, this would have resulted in significant losses of finished product. Because the blanks we were moulding were relatively short a significant number of blanks contained sniped ends.

Forbes et al., (1997) highlighted the importance of properly machining lumber before edge-gluing. The edges of lumber are critically important in order to obtain quality edge-glued panels:

- Edges must be surfaced smoothly and straight from end to end,

- Edges must be parallel,

- Edges must not be burnt from sawing,

- And edges must be free of loose fibers.

Saw blades and cutter knives must be properly sharpened to prevent burning or tearout. Lumber that is visibly burnt is obviously not suitable for edgegluing processes as glue will not adhere properly to the surface. In addition, wood that is not burnt but just burnished will also not be suitable for gluing. Burnishing may be hard to identify. The sawn surface may be lustrous but does not appear to be burned (Forbes et al. 2003). Also, dull knives may result in fuzzy or raised grain which also complicates edge-gluing.

Once quality surfaced material is obtained, material must be edge-glued using the correct magnitude of pressure (Table 4.15). In general, the denser the species of wood, the more pressure needs to be applied. 
Table 4.15 Required clamping pressure for obtaining quality edge-glued joints for various species.

\begin{tabular}{clc}
\hline \hline Density & Examples of Species & $\begin{array}{c}\text { Required Clamping } \\
\text { Pressure(psi) }\end{array}$ \\
\hline \hline High & ash, hard maple, oak & $200-250$ \\
Medium & $\begin{array}{l}\text { cherry, soft maple, } \\
\text { yellow-poplar }\end{array}$ & $150-200$ \\
Low & basswood, fir, pine & $100-150$ \\
\hline \hline
\end{tabular}

Another major concern regarding the manufacture of edge-glued panels is moisture content. It is critical that all staves that make up a panel are of equal moisture content. Mitchell et al., (2003) discussed this issue in detail. Even small changes in moisture content can result in problems with finished panels. If panels are produced and machined to finished dimension with constituent material of varying $\mathrm{MC}$, the panel will appear to be uniform until the panel has a chance to fully equilibrate. After equilibration, panels will change dimensions resulting in inferior panels.

Moisture content must be properly maintained in the rough mill to ensure properly dimensioned panels. Because wood shrinks and swells near the ends and surface, small defects can occur quickly between the time the blanks are surfaced and the time they are edge-glued. This is especially true in winter when the relative humidity and EMC may be very low.

Finger-jointed, edge-glued panels create more complications in this regard because, as noted before, a panel could be made up from as many as 63 pieces 
of lumber. These pieces certainly come from different parts of a tree and different trees, resulting in differences in how the individual pieces react to moisture content. The ring orientation determines how a panel will shrink/sell as well as appear. This is where sorting of ring orientation becomes a valuable process. The combination of color matching and grain matching can greatly increase the aesthetics as well as improve the quality of panels.

Color matching software exists to aid in the sorting and production of finger-jointed blanks. This is a relatively complex material handling and sorting process, where the many small shorts need to be efficiently sorted by color and ring orientation before finger-jointing. The benefits are numerous, however.

The appearance of flat grained lumber varies widely as compared to vertically oriented lumber. Ring orientation can play a major role in finishing panels because flat grained lumber takes stains and finishes differently than quarter-sawn lumber (Jourdain, 1999). If a panel consists of many different individual pieces as in this study, the appearance of the panel will be dictated by the worst looking piece. For example if the panel consists of all quarter-sawn pieces except one flat-grain, the finishing and appearance will be only as good as the one flat-grained piece. Therefore, much care must be taken to produce visually appealing panels. Based on this fact, lower value lumber, such as yellow-poplar, may not be suitable for such processes. Recent advancements have been made in scanning technologies to automate color sorting and grain matching and will help to improve the efficiency of these processes. 


\section{SUMMARY AND CONCLUSIONS}

Methods to improve recovery of low-quality lumber were investigated. $4,800 \mathrm{BF}$ of $4 / 4$ thickness, low-grade (3AC) lumber was salvaged to obtain maximum yield based on small cutting-sizes. The resultant material was measured and used to determine yields and size distribution of each species. Material was then finger-jointed and edge-glued into panels for use in the furniture or cabinet industries. Mechanical properties of the finger-jointed lumber were evaluated. The yields of finished products were determined for each species. Also, a cost-benefit analysis was performed to evaluate the feasibility of the process.

Based on the findings of this research, the following conclusions may be drawn:

- Yellow-poplar lumber produced the highest yield of usable wood of the species investigated; followed by red oak, cherry and soft maple.

- Both horizontal and vertical finger-jointing methods provided sufficient mechanical strength for their intended end-use.

- The ratio of converting No. 3A Common lumber into finger-jointed, edgeglued panels was approximately $38 \%$ for yellow-poplar, $35 \%$ for red oak, and approximately $31 \%$ for cherry and soft maple.

- Based on the current value of edge-glued panels, cherry and red oak were the most profitable species to process. 
The results should be interpreted with care as they specific to the species investigated and may not be universally applied to all lumber. A more in-depth economic analysis should be undertaken to better determine the feasibility of the processes. As the supply of quality timber continues to become scarcer, market demand for finger-jointed, edge-glued panels may increase. 


\section{List of References}

American Society for Testing and Materials. 2006. Standard Test Methods for Small Clear Specimens of Timber. ASTM D 143-94. ASTM, West Conshohocken, PA.

American Society for Testing and Materials. 2006. Standard Test Methods for Evaluating Properties of Wood-Base Fiber and Particle Panel Materials. ASTM D 1037-99. ASTM, West Conshohocken, PA.

Araman, P., B.G. Hansen. The Dollars and Cents of Conventional Processing of Standard-Size Blanks. Res. Pap.NE-INF-43-83. Broomall, PA: U.S. Department of Agriculture, Forest Service, Northeastern Forest Experiment Station; 1983.

Buehlmann, U. 1998. Understanding the relationship of lumber yield and cutting bill requirements: a statistical approach. PhD. Dissertation, Virginia Polytechnic Institute and State University, Blacksburg, VA.

Buehlmann, U., J.K. Wiedenbeck, D.E. Kline. 1999. Character marked furniture: potential for lumber yield increase in crosscut-first rough mills. Forest Products Journal. 49(2): 65-72. 
Buehlmann, U, M. Bumbargardner, A. Schuler, and M. Barford. 2007. Assessing the impacts of global competition on the Appalachian hardwood industry. Forest Products Journal. 57(3): 89-93.

Bumgardner, M., B. Hansen, A. Schuler, and P.A. Araman. 2001. Options for Small-diameter hardwood utilization: Past and present. In: Proc. Of the Southern Forest Economics Workers Annual Meeting. SOFEW, Lexington, KY.

Cumbo, D.W., R.L. Smith and P. Araman. 2003. Low-grade hardwood lumber production, markets, and issues. Forest Products Journal. 53(9):17-24.

Cumbo, D.W., R.L. Smith, and C.W. Becker III. 2004. Value analysis of lumber produced from small-diameter timber. Forest Products Journal. 54(10):29-34.

Forbes, Craig. 1997. "Quality Control for Edge Glued Panel Manufacturing” Wood Products Notes. North Carolina State University. Raleigh, NC.

Forest Products Laboratory. 1999. Wood Handbook: Wood as an Engineering material. FPL-GTR-113. USDA Forest Products Laboratory, Madison, WI: pp. 3$6,15-5$.

Hardwood Market Report. 2008. Hardwood Market Report. LXXXVI(36):4-5 
Jokerst, Ronald W. 1981. Finger jointed wood products, Madison, Wis., Forest Products Laboratory, (USDA For. Serv. Res. Pap. FPL 382): pp.2-5.

Jourdain, C. 1999. Changing nature of wood products- What does it mean for coatings and finish performance. Journal of Coatings Technology. 71(890):61-66.

Lang, Elemer M. and Hassler Curt 2000. Evaluating Mechanical Properties of Finger-Jointed Pallet Stock When Glued at Green Moisture Content. Final Technical Report to the USDA, Forest Service. Division of Forestry, Morgantown, WV: pp.1-9.

Lin, W., D.E. Kline, P.A. Araman, and J.K. Wiedenbeck. 1995. Design and evaluation of log-to-dimension manufacturing systems using system simulation. Forest Products Journal. 45(3):37-44.

Mitchell, Philip H., J. Wiedenbeck and B. Ammerman. 2003. Rough Mill Improvement Guide for Managers and Supervisors. General Technical Report NE-329: pp. 50-56

River, Bryan H. and E.A. Okkonen. 1991. Delamination of Edge-Glued Wood Panels: Moisture Effects. Res. note FPL-RN-0259. Madison, WI: U.S. Department of Agriculture, Forest Service, FPL: 2-10. 
Shepley, B. P., J. Wiedenbeck, and R. L. Smith. 2004. Opportunities for expanded and higher value utilization of No. 3A Common hardwood. Forest Products Journal. 54(9):77-85.

SigmaPlot. 2003. Version 8.0. SPSS Inc. Chicago, IL.

SigmaStat. 1999. Version 3.0. SPSS Inc. Chicago IL.

Smith, Bob. 1997 "Exploring Value-Added Options." Virginia Forest Products Association (Aug. 1997):9-19.

Steele, P. H., J. Wiedenbeck, R. Shmulky, and A. Perera. 1999. The influence of lumber grade on machine productivity in the rough mill. Forest Products Journal. 49(9):48-54 .

"Titebond® II Premium Wood Glue" www.Titebond.com 8 Aug. 2008 $<$ http://www.titebond.com/IntroPageTB.ASP?UserType=1\&ProdSel= MSDSSelectorTB.asp>

Wiedenbeck, J., B.P. Shepley, R.L. Smith. 2004 Rough-mill yield and cutting efficiency for No. 3A Common lumber compared to other lumber grade mix options. Forest Products Journal. 54(12):132-140. 
Zuo, X., U. Buehlmann, R.E. Thomas. 2003. Lumber Cost Minimization through Optimum Grade-Mix Selection. Electronic Proceedings from: Virginia Tech $17^{\text {th }}$ International Conference on Production Research August 3-7, 2003. 


\section{Appendices}

\section{Appendix I. Results of One-Way ANOVA for size distributions of clear shorts for all species.}

One Way Analysis of Variance

Data source: Data 1 in All Species widths

Normality Test: $\quad$ Failed $(P=<0.001)$

Test execution ended by user request, ANOVA on Ranks begun

Kruskal-Wallis One Way Analysis of Variance on RanksTuesday, August 12, 2008, 11:17:02 PM

Data source: Data 1 in All species widths

$\begin{array}{lcccccc}\text { Group } & \text { N } & \text { Missing } & \text { Median } & \mathbf{2 5 \%} & \mathbf{7 5 \%} & \\ \text { Cherry-width } & 1026 & 0 & 2.875 & 2.125 & 3.500 & \\ \text { Maple-width } & 1039 & 0 & 2.625 & 2.000 & 3.500 & \\ \text { Oak-width } & 1051 & 0 & 3.000 & 2.250 & 3.750 & \\ \text { Yellow-poplar-width } & 1457 & 0 & 2.625 & 2.125 & 3.125 \\ \text { H= 91.122 with 3 degrees of freedom. }(\mathrm{P}=<0.001) & & \end{array}$

The differences in the median values among the treatment groups are greater than would be expected by chance; there is a statistically significant difference $(P=<0.001)$

To isolate the group or groups that differ from the others use a multiple comparison procedure.

All Pairwise Multiple Comparison Procedures (Dunn's Method) :

Comparison

Diff of Ranks $\quad \mathrm{Q} \quad \mathrm{P}<0.05$ 


$\begin{array}{lrrr}\text { Oak-width vs Yellow-poplar-width } & 476.313 & 8.915 & \text { Yes } \\ \text { Oak-width vs Maple-width } & 393.953 & 6.821 & \text { Yes } \\ \text { Oak-width vs Cherry-width } & 199.109 & 3.436 & \text { Yes } \\ \text { Cherry-width vs Yellow-poplar-width } & 277.204 & 5.152 & \text { Yes } \\ \text { Cherry-width vs Maple-width } & 194.843 & 3.353 & \text { Yes } \\ \text { Maple-width vs Yellow-poplar-width } & 82.360 & 1.536 & \text { No }\end{array}$

Note: The multiple comparisons on ranks do not include an adjustment for ties.

One Way Analysis of Variance

Tuesday, October 07, 2008, 11:25:02 PM

Data source: Data 1 in All Species lengths

Normality Test: $\quad$ Failed $(P=<0.001)$

Test execution ended by user request, ANOVA on Ranks begun

Kruskal-Wallis One Way Analysis of Variance on RanksTuesday, October 07, 2008, 11:25:02 PM

Data source: Data 1 in All Species lengths

$\begin{array}{lcccccc}\text { Group } & \text { N } & \text { Missing } & \text { Median } & \mathbf{2 5 \%} & \mathbf{7 5 \%} & \\ \text { Cherry-length } & 1026 & 0 & 20.063 & 14.625 & 28.000 & \\ \text { Maple-length } & 1039 & 0 & 19.625 & 15.000 & 27.000 & \\ \text { Oak-length } & 1051 & 0 & 19.875 & 14.281 & 28.344 & \\ \text { Yellow-poplar-length } & 1457 & 0 & 17.750 & 13.750 & 25.031\end{array}$

$H=45.344$ with 3 degrees of freedom. $(P=<0.001)$

The differences in the median values among the treatment groups are greater than would be expected by chance; there is a statistically significant difference $(P=<0.001)$

To isolate the group or groups that differ from the others use a multiple comparison procedure. 
All Pairwise Multiple Comparison Procedures (Dunn's Method) :

$\begin{array}{lrrr}\text { Comparison } & \text { Diff of Ranks } & \text { Q } & \text { P<0.05 } \\ \text { Cherry-length vs Yellow-poplar-length } & 313.227 & 5.821 & \text { Yes } \\ \text { Cherry-length vs Oak-length } & 54.496 & 0.941 & \text { No } \\ \text { Cherry-length vs Maple-length } & 47.914 & 0.825 & \text { No } \\ \text { Maple-length vs Yellow-poplar-length } & 265.313 & 4.949 & \text { Yes } \\ \text { Maple-length vs Oak-length } & 6.582 & 0.114 & \text { No } \\ \text { Oak-length vs Yellow-poplar-length } & 258.731 & 4.842 & \text { Yes }\end{array}$

Note: The multiple comparisons on ranks do not include an adjustment for ties.

One Way Analysis of Variance

Tuesday, October 07, 2008, 11:27:06 PM

Data source: Data 1 in All Species volumes

Normality Test: $\quad$ Failed $(P=<0.001)$

Test execution ended by user request, ANOVA on Ranks begun

Kruskal-Wallis One Way Analysis of Variance on RanksTuesday, October 07, 2008, 11:27:06 PM

Data source: Data 1 in All Species volumes

$\begin{array}{lcccccc}\text { Group } & \text { N } & \text { Missing } & \text { Median } & \mathbf{2 5 \%} & \mathbf{7 5 \%} & \\ \text { Cherry-volume } 1026 & 0 & 56.820 & 37.875 & 84.813 & \\ \text { Maple-volume } & 1039 & 0 & 52.938 & 32.121 & 83.672 & \\ \text { Oak-volume } & 1051 & 0 & 58.188 & 37.992 & 90.012 & \\ \text { Yellow-poplar-volume } & 1457 & 0 & 46.219 & 31.492 & 70.441\end{array}$

$H=86.186$ with 3 degrees of freedom. $(P=<0.001)$ 
The differences in the median values among the treatment groups are greater than would be expected by chance; there is a statistically significant difference $(P=<0.001)$

To isolate the group or groups that differ from the others use a multiple comparison procedure.

All Pairwise Multiple Comparison Procedures (Dunn's Method) :

$\begin{array}{lccc}\text { Comparison } & \text { Diff of Ranks } & \mathbf{Q} & \text { P<0.05 } \\ \text { Oak-volume vs Yellow-poplar-volume } & 446.364 & 8.354 & \text { Yes } \\ \text { Oak-volume vs Maple-volume } & 226.716 & 3.925 & \text { Yes } \\ \text { Oak-volume vs Cherry-volume } & 62.869 & 1.085 & \text { No } \\ \text { Cherry-volume vs Yellow-poplar-volume383.495 } & 7.127 & \text { Yes } \\ \text { Cherry-volume vs Maple-volume } & 163.846 & 2.820 & \text { Yes } \\ \text { Maple-volume vs Yellow-poplar-volume219.649 } & 4.097 & \text { Yes }\end{array}$

Note: The multiple comparisons on ranks do not include an adjustment for ties. 


\section{Appendix II. Results of One-Way ANOVA for Mechanical Testing}

One Way Analysis of Variance

Data source: Data 1 in all FJ mechanical props
Monday, December 22, 2008, 11:30:51 AM

Normality Test: $\quad$ Passed $(\mathrm{P}>0.050)$

Equal Variance Test: $\quad$ Passed $\quad(P=0.930)$

\begin{tabular}{lccrcc} 
Group Name & N & Missing & \multicolumn{1}{c}{ Mean } & Std Dev & SEM \\
CV-mor & 10 & 0 & 10472.335 & 1318.346 & 416.898 \\
CH-mor & 10 & 0 & 7466.529 & 1553.607 & 491.294 \\
CS-mor & 10 & 0 & 12337.382 & 1775.930 & 561.598
\end{tabular}

$\begin{array}{lrrrrc}\text { Source of Variation } & \text { DF } & \text { SS } & \text { MS } & \text { F } & \text { P } \\ \text { Between Groups } & 2 & 120794944.955 & 60397472.478 & 24.802 & <0.001 \\ \text { Residual } & 27 & 65750910.226 & 2435218.897 & & \\ \text { Total } & 29 & 186545855.181 & & & \end{array}$

The differences in the mean values among the treatment groups are greater than would be expected by chance; there is a statistically significant difference $(\mathrm{P}=<0.001)$.

Power of performed test with alpha $=0.050: 1.000$

All Pairwise Multiple Comparison Procedures (Holm-Sidak method):

Overall significance level $=0.05$

Comparisons for factor:

$\begin{array}{lccccc}\text { Comparison } & \text { Diff of Means } & \mathbf{t} & \text { Unadjusted P } & \text { Critical Level } & \text { Significant? } \\ \text { CS-mor vs. CH-mor } & 4870.853 & 6.979 & <0.001 & 0.017 & \text { Yes } \\ \text { CV-mor vs. CH-mor } & 3005.806 & 4.307 & <0.001 & 0.025 & \text { Yes } \\ \text { CS-mor vs. CV-mor } & 1865.047 & 2.672 & 0.013 & 0.050 & \text { Yes }\end{array}$


Data source: Data 1 in all FJ mechanical props

Normality Test: $\quad$ Passed $(\mathrm{P}>0.050)$

Equal Variance Test: $\quad$ Passed $\quad(P=0.594)$

$\begin{array}{lccccc}\text { Group Name } & \mathbf{N} & \text { Missing } & \text { Mean } & \text { Std Dev } & \text { SEM } \\ \text { CV-moe } & 10 & 0 & 1.475 & 0.194 & 0.0613 \\ \text { CH-moe } & 10 & 0 & 1.336 & 0.0956 & 0.0302 \\ \text { CS-moe } & 10 & 0 & 1.618 & 0.135 & 0.0428\end{array}$

$\begin{array}{lrcccc}\text { Source of Variation } & \text { DF } & \text { SS } & \text { MS } & \text { F } & \text { P } \\ \text { Between Groups } & 2 & 0.398 & 0.199 & 9.176 & <0.001 \\ \text { Residual } & 27 & 0.585 & 0.0217 & & \\ \text { Total } & 29 & 0.983 & & & \end{array}$

The differences in the mean values among the treatment groups are greater than would be expected by chance; there is a statistically significant difference $(\mathrm{P}=<0.001)$.

Power of performed test with alpha $=0.050: 0.948$

All Pairwise Multiple Comparison Procedures (Holm-Sidak method):

Overall significance level $=0.05$

Comparisons for factor:

\begin{tabular}{lccccc} 
Comparison & Diff of Means & $\mathbf{t}$ & Unadjusted P & Critical Level & \multicolumn{2}{c}{ Significant? } \\
CS-moe vs. CH-moe & 0.282 & 4.284 & $<0.001$ & 0.017 & Yes \\
CS-moe vs. CV-moe & 0.143 & 2.174 & 0.039 & 0.025 & Yes \\
CV-moe vs. CH-moe & 0.139 & 2.110 & 0.044 & 0.050 & Yes
\end{tabular}

Data source: Data 1 in all FJ mechanical props 
Normality Test: $\quad$ Passed $(\mathrm{P}>0.050)$

Equal Variance Test: $\quad$ Failed $\quad(P=0.002)$

Test execution ended by user request, ANOVA on Ranks begun

Kruskal-Wallis One Way Analysis of Variance on Ranks $\quad$ Monday, December 22, 2008, 11:34:58 AM

Data source: Data 1 in all FJ mechanical props

\begin{tabular}{|c|c|c|c|c|}
\hline Group $\mathbf{N}$ & Missing & Median & $25 \%$ & $75 \%$ \\
\hline MV-mor 10 & 0 & 10533.182 & 9385.687 & 11812.467 \\
\hline MH-mor 10 & 0 & 8581.974 & 8382.873 & 9538.260 \\
\hline MS-mor 10 & 0 & 15377.295 & 11358.276 & 17800.853 \\
\hline
\end{tabular}

$\mathrm{H}=18.041$ with 2 degrees of freedom. $(\mathrm{P}=<0.001)$

The differences in the median values among the treatment groups are greater than would be expected by chance; there is a statistically significant difference $(\mathrm{P}=<0.001)$

To isolate the group or groups that differ from the others use a multiple comparison procedure.

All Pairwise Multiple Comparison Procedures (Dunn's Method) :

$\begin{array}{lccc}\text { Comparison } & \text { Diff of Ranks } & \mathbf{Q} & \mathbf{P}<\mathbf{0 . 0 5} \\ \text { MS-mor vs MH-mor } & 16.700 & 4.242 & \text { Yes } \\ \text { MS-mor vs MV-mor } & 9.100 & 2.311 & \text { No } \\ \text { MV-mor vs MH-mor } & 7.600 & 1.930 & \text { No }\end{array}$

Note: The multiple comparisons on ranks do not include an adjustment for ties.

One Way Analysis of Variance

Monday, December 22, 2008, 11:44:06 AM

Data source: Data 1 in all FJ mechanical props 
Normality Test: $\quad$ Passed $(\mathrm{P}>0.050)$

Equal Variance Test: $\quad$ Passed $\quad(P=0.221)$

$\begin{array}{lccccc}\text { Group Name } & \text { N } & \text { Missing } & \text { Mean } & \text { Std Dev } & \text { SEM } \\ \text { MV-moe } & 10 & 0 & 1.367 & 0.210 & 0.0664 \\ \text { MH-moe } & 10 & 0 & 1.349 & 0.140 & 0.0443 \\ \text { MS-moe } & 10 & 0 & 1.618 & 0.246 & 0.0777\end{array}$

$\begin{array}{lrcccc}\text { Source of Variation } & \text { DF } & \text { SS } & \text { MS } & \text { F } & \text { P } \\ \text { Between Groups } & 2 & 0.453 & 0.226 & 5.473 & 0.010 \\ \text { Residual } & 27 & 1.117 & 0.0414 & & \\ \text { Total } & 29 & 1.570 & & & \end{array}$

The differences in the mean values among the treatment groups are greater than would be expected by chance; there is a statistically significant difference $(\mathrm{P}=0.010)$.

Power of performed test with alpha $=0.050: 0.720$

The power of the performed test (0.720) is below the desired power of 0.800 .

You should interpret the negative findings cautiously.

All Pairwise Multiple Comparison Procedures (Holm-Sidak method):

Overall significance level $=0.05$

Comparisons for factor:

$\begin{array}{lccccc}\text { Comparison } & \text { Diff of Means } & \mathbf{t} & \text { Unadjusted P } & \text { Critical Level } & \text { Significant? } \\ \text { MS-moe vs. MH-moe } & 0.269 & 2.957 & 0.006 & 0.017 & \text { Yes } \\ \text { MS-moe vs. MV-moe } & 0.251 & 2.764 & 0.010 & 0.025 & \text { Yes } \\ \text { MV-moe vs. MH-moe } & 0.0176 & 0.193 & 0.848 & 0.050 & \text { No }\end{array}$

One Way Analysis of Variance Monday, December 22, 2008, 11:37:10 AM

Data source: Data 1 in all FJ mechanical props 
Normality Test: $\quad$ Passed $\quad(\mathrm{P}>0.050)$

Equal Variance Test: $\quad$ Passed $\quad(P=0.780)$

$\begin{array}{lccccc}\text { Group Name } & \text { N } & \text { Missing } & \text { Mean } & \text { Std Dev } & \text { SEM } \\ \text { OV-mor } & 10 & 0 & 8930.983 & 2055.179 & 649.905 \\ \text { OH-mor } & 10 & 0 & 8510.788 & 1687.243 & 533.553 \\ \text { OS-mor } & 10 & 0 & 19261.210 & 3162.563 & 1000.090\end{array}$

$\begin{array}{lrcrrc}\text { Source of Variation } & \text { DF } & \text { SS } & \text { MS } & \text { F } & \text { P } \\ \text { Between Groups } & 2 & 741539148.458 & 370769574.229 & 65.153 & <0.001 \\ \text { Residual } & 27 & 153651212.379 & 5690785.644 & & \\ \text { Total } & 29 & 895190360.836 & & & \end{array}$

The differences in the mean values among the treatment groups are greater than would be expected by chance; there is a statistically significant difference $(\mathrm{P}=<0.001)$.

Power of performed test with alpha $=0.050: 1.000$

All Pairwise Multiple Comparison Procedures (Holm-Sidak method):

Overall significance level $=0.05$

Comparisons for factor:

$\begin{array}{lrrrrr}\text { Comparison } & \text { Diff of Means } & \text { t } & \text { Unadjusted P } & \text { Critical Level } & \text { Significant? } \\ \text { OS-mor vs. OH-mor } & 10750.423 & 10.077 & <0.001 & 0.017 & \text { Yes } \\ \text { OS-mor vs. OV-mor } & 10330.227 & 9.683 & <0.001 & 0.025 & \text { Yes } \\ \text { OV-mor vs. OH-mor } & 420.196 & 0.394 & 0.697 & 0.050 & \text { No }\end{array}$

One Way Analysis of Variance

Monday, December 22, 2008, 11:38:06 AM

Data source: Data 1 in all FJ mechanical props

Normality Test: $\quad$ Passed $(\mathrm{P}>0.050)$ 
Equal Variance Test: $\quad$ Passed $\quad(P=0.597)$

$\begin{array}{lccccl}\text { Group Name } & \mathbf{N} & \text { Missing } & \text { Mean } & \text { Std Dev } & \text { SEM } \\ \text { OV-moe } & 10 & 0 & 1.684 & 0.196 & 0.0621 \\ \text { OH-moe } & 10 & 0 & 1.615 & 0.185 & 0.0584 \\ \text { OS-moe } & 10 & 0 & 1.983 & 0.354 & 0.112\end{array}$

$\begin{array}{lrcccc}\text { Source of Variation } & \text { DF } & \text { SS } & \text { MS } & \text { F } & \text { P } \\ \text { Between Groups } & 2 & 0.765 & 0.383 & 5.792 & 0.008 \\ \text { Residual } & 27 & 1.784 & 0.0661 & & \\ \text { Total } & 29 & 2.549 & & & \end{array}$

The differences in the mean values among the treatment groups are greater than would be expected by chance; there is a statistically significant difference $(\mathrm{P}=0.008)$.

Power of performed test with alpha $=0.050: 0.753$

The power of the performed test (0.753) is below the desired power of 0.800 .

You should interpret the negative findings cautiously.

All Pairwise Multiple Comparison Procedures (Holm-Sidak method):

Overall significance level $=0.05$

Comparisons for factor:

$\begin{array}{lccccc}\text { Comparison } & \text { Diff of Means } & \mathbf{t} & \text { Unadjusted P } & \text { Critical Level } & \text { Significant? } \\ \text { OS-moe vs. OH-moe } & 0.368 & 3.202 & 0.003 & 0.017 & \text { Yes } \\ \text { OS-moe vs. OV-moe } & 0.299 & 2.601 & 0.015 & 0.025 & \text { Yes } \\ \text { OV-moe vs. OH-moe } & 0.0690 & 0.600 & 0.553 & 0.050 & \text { No }\end{array}$




\section{Appendix III. Results of One-Way ANOVA for 'shorts' size distribution}

One Way Analysis of Variance

Data source: Data 1 in All species

Normality Test: $\quad$ Failed $\quad(P=<0.001)$
Saturday, July 12, 2008, 8:17:36 PM

Test execution ended by user request, ANOVA on Ranks begun

Kruskal-Wallis One Way Analysis of Variance on Ranks

Saturday, July 12, 2008, 8:17:36 PM

Data source: Data 1 in All species

$\begin{array}{lccccc}\text { Group } & \mathbf{N} & \text { Missing } & \text { Median } & \mathbf{2 5 \%} & \mathbf{7 5 \%} \\ \text { Cherry-width } & 1026 & 0 & 2.875 & 2.125 & 3.500 \\ \text { Maple-width } & 1039 & 0 & 2.625 & 2.000 & 3.500 \\ \text { Oak-width } & 1051 & 0 & 3.000 & 2.250 & 3.750 \\ \text { Yellow-poplar-width1457 } & 0 & 2.625 & 2.125 & 3.125\end{array}$

$\mathrm{H}=91.122$ with 3 degrees of freedom. $(\mathrm{P}=<0.001)$

The differences in the median values among the treatment groups are greater than would be expected by chance; there is a statistically significant difference $(\mathrm{P}=<0.001)$

To isolate the group or groups that differ from the others use a multiple comparison procedure.

All Pairwise Multiple Comparison Procedures (Dunn's Method) :

$\begin{array}{lccc}\text { Comparison } & \text { Diff of Ranks } & \mathbf{Q} & \mathbf{P}<\mathbf{0 . 0 5} \\ \text { Oak-width vs Yellow-poplar-width } & 476.313 & 8.915 & \text { Yes } \\ \text { Oak-width vs Maple-width } & 393.953 & 6.821 & \text { Yes } \\ \text { Oak-width vs Cherry-width } & 199.109 & 3.436 & \text { Yes } \\ \text { Cherry-width vs Yellow-poplar-width } & 277.204 & 5.152 & \text { Yes } \\ \text { Cherry-width vs Maple-width } & 194.843 & 3.353 & \text { Yes }\end{array}$


Note: The multiple comparisons on ranks do not include an adjustment for ties.

One Way Analysis of Variance

Data source: Data 1 in All species
Saturday, July 12, 2008, 8:18:06 PM

Normality Test: $\quad$ Failed $\quad(\mathrm{P}=<0.001)$

Test execution ended by user request, ANOVA on Ranks begun

Kruskal-Wallis One Way Analysis of Variance on Ranks

Data source: Data 1 in All species

$\begin{array}{lccccc}\text { Group } & \mathbf{N} & \text { Missing } & \text { Median } & \mathbf{2 5 \%} & \mathbf{7 5 \%} \\ \text { Cherry-length } & 1026 & 0 & 20.063 & 14.625 & 28.000 \\ \text { Maple-length } & 1039 & 0 & 19.625 & 15.000 & 27.000 \\ \text { Oak-length } & 1051 & 0 & 19.875 & 14.281 & 28.344 \\ \text { Yellow-poplar-length1457 } & 0 & 17.750 & 13.750 & 25.031\end{array}$

$\mathrm{H}=45.344$ with 3 degrees of freedom. $(\mathrm{P}=<0.001)$

The differences in the median values among the treatment groups are greater than would be expected by chance; there is a statistically significant difference $(\mathrm{P}=<0.001)$

To isolate the group or groups that differ from the others use a multiple comparison procedure.

All Pairwise Multiple Comparison Procedures (Dunn's Method) :

Comparison $\quad$ Diff of Ranks $\quad$ Q $\quad \mathbf{P}<\mathbf{0 . 0 5}$




$\begin{array}{lrrr}\text { Cherry-length vs Yellow-poplar-length } & 313.227 & 5.821 & \text { Yes } \\ \text { Cherry-length vs Oak-length } & 54.496 & 0.941 & \text { No } \\ \text { Cherry-length vs Maple-length } & 47.914 & 0.825 & \text { Do Not Test } \\ \text { Maple-length vs Yellow-poplar-length } & 265.313 & 4.949 & \text { Yes } \\ \text { Maple-length vs Oak-length } & 6.582 & 0.114 & \text { Do Not Test } \\ \text { Oak-length vs Yellow-poplar-length } & 258.731 & 4.842 & \text { Yes }\end{array}$

Note: The multiple comparisons on ranks do not include an adjustment for ties.

One Way Analysis of Variance

Data source: Data 1 in All species

Normality Test: $\quad$ Failed $\quad(\mathrm{P}=<0.001)$
Saturday, July 12, 2008, 8:18:29 PM

Test execution ended by user request, ANOVA on Ranks begun

Kruskal-Wallis One Way Analysis of Variance on Ranks

Saturday, July 12, 2008, 8:18:29 PM

Data source: Data 1 in All species

$\begin{array}{lcccccc}\text { Group } & \text { N } & \text { Missing } & \text { Median } & \mathbf{2 5 \%} & \mathbf{7 5 \%} & \\ \text { Cherry-volume } & 1026 & 0 & 56.820 & 37.875 & 84.813 & \\ \text { Maple-volume } & 1039 & 0 & 52.938 & 32.121 & 83.672 & \\ \text { Oak-volume } & 1051 & 0 & 58.188 & 37.992 & 90.012 & \\ \text { Yellow-poplar-volume } & 1457 & 0 & 46.219 & 31.492 & 70.441 \\ \text { H = 86.186 with 3 degrees of freedom. }(\mathrm{P}=<0.001) & & & & \end{array}$

The differences in the median values among the treatment groups are greater than would be expected by chance; there is a statistically significant difference $(\mathrm{P}=<0.001)$

To isolate the group or groups that differ from the others use a multiple comparison procedure. 
All Pairwise Multiple Comparison Procedures (Dunn's Method) :

$\begin{array}{lccc}\text { Comparison } & \text { Diff of Ranks } & \mathbf{Q} & \mathbf{P}<\mathbf{0 . 0 5} \\ \text { Oak-volume vs Yellow-poplar-volume } & 446.364 & 8.354 & \text { Yes } \\ \text { Oak-volume vs Maple-volume } & 226.716 & 3.925 & \text { Yes } \\ \text { Oak-volume vs Cherry-volume } & 62.869 & 1.085 & \text { No } \\ \text { Cherry-volume vs Yellow-poplar-volume } & 383.495 & 7.127 & \text { Yes } \\ \text { Cherry-volume vs Maple-volume } & 163.846 & 2.820 & \text { Yes } \\ \text { Maple-volume vs Yellow-poplar-volume } & 219.649 & 4.097 & \text { Yes }\end{array}$

Note: The multiple comparisons on ranks do not include an adjustment for ties. 